\title{
Ethylene production via catalytic dehydration of diluted bioethanol: a step towards an integrated biorefinery
}

Ilenia Rossetti ${ }^{*}$, Matteo Compagnoni ${ }^{1}$, Elisabetta Finocchio², Gianguido Ramis ${ }^{2}$, Alessandro Di Michele ${ }^{3}$, Yannick Millot ${ }^{4}$, Stanislaw Dzwigaju, ${ }^{*}$

${ }^{1}$ Dip. Chimica, Università degli Studi di Milano, INSTM Unit Milano-Università and CNRISTM, via C. Golgi, 19, I-20133 Milano, Italy

2 Dip. di Ingegneria Civile, Chimica e Ambientale, Università degli Studi di Genova, P.le J.F. Kennedy 1, I-16129, Genova, Italy and INSTM Unit Genova

${ }^{3}$ Dip. di Fisica - Università degli Studi di Perugia, Via Pascoli, 06123 Perugia

4 Sorbonne Universités, UPMC Univ Paris 06, CNRS, UMR 7197, Laboratoire de Réactivité de Surface, F-75005, 4 place Jussieu, Paris, France

\section{ABSTRACT}

After a preliminary thermodynamic investigation, proper operating conditions have been selected to maximize ethylene productivity by ethanol dehydration and limit side products such as coke and higher olefins or oxygenates. We focused on the possibility to operate with a diluted bioethanol solution (ca. 50 wt\%), which represents a promising and convenient raw material, obtainable by simple flash concentration of the fermentation broth. Furthermore, water addition to the ethanol dehydration reactor may help preventing catalyst coking and diethyl ether formation, although affecting the thermodynamic products 
distribution. A proof of concept for an ethanol dehydration process using diluted ethanol is also provided through process simulation.

Catalysts based on a BEA zeolite have been compared, characterized by different acidity imparted by dealumination treatments. Ni addition in variable loading helped suppressing undesired byproducts, difficult to separate from ethylene. For instance, no trace of diethyl ether nor acetaldehyde has been observed for the Ni-loaded samples under optimized working conditions.

Catalyst characterization by FT IR allowed correlating a high selectivity to ethylene with the acid sites nature of the catalyst, whereas the presence of extraframework Lewis acidic sites induced faster coke formation.

Durability was finally checked on the most active and selective catalyst evidencing stable operation for 80 h-on-stream and without evidence of coke deposition, as determined after characterization of the spent samples. $\mathrm{A} \gamma-\mathrm{Al}_{2} \mathrm{O}_{3}$ catalyst has been tested as benchmark under the same conditions.

Keywords: Ethylene production; Ni catalysts; BEA zeolite; Bioethanol conversion to chemicals; Acid site.

\section{1 - INTRODUCTION}

At present, about $75 \%$ of petrochemical products are produced from ethylene, including acetaldehyde, acetic acid, ethylene oxide, ethylene glycol, ethylbenzene, chloroethanol, vinyl chloride, styrene, ethylene dichloride and vinyl acetate. It is also used as monomer to produce a variety of important products such as polyethylene, polyvinyl chloride and 
polystyrene. Ethylene production has been considered as one of the indicators to measure the petrochemical development level of countries all over the world.

In 2006, the ethylene global production was around 113 million tons and the main process for ethylene production at present is cracking of hydrocarbons, leading to ca. $99 \%$ of ethylene worldwide [1,2].

To exploit new renewable based feedstocks for ethylene production, in an integrated biorefinery concept, biomass-derived ethanol can be catalytically dehydrated as a sustainable alternative route $[3,4]$. In this frame, the bio-based polymers market is extensively growing (1.3 billion US dollar market with 35\% growth between 2006 and 2011). The demand for renewable polyethylene (PE) corresponds to $10 \%$ of the global PE market whereas the present supply is $<1 \%$. However, for viable processes, a premium price for the products and/or low-cost feedstock are required and this point is still challenging [5]. Therefore, routes to ethylene starting from inexpensive feedstocks should be explored.

A sugar-to-ethylene approach [6,7] has already been commercially operated in Brazil [6] and the economic feasibility of this route has hardly been studied in other parts of the world [8]. Recent work includes the use of second generation biomass (bagasse) for the production of fuel and chemical-grade ethanol [9].

The availability of second generation bioethanol with reasonable price [10] may open the way to this important step towards the exploitation of biorefineries. However, the unit operations to achieve the concentration and final dehydration of the fermentation broth hugely affect bioethanol price, especially when $>99 \%$ purity is required, as for direct combustion or gasoline blending purposes. Therefore, the possibility to use less concentrated bioethanol solutions as feedstock is an important step towards the economical sustainability of the process. 
Ethylene may be produced through ethanol dehydration, catalyzed by acidic active sites. The reaction is endothermal and commonly heat is provided by cofeeding steam, which also allows to prevent catalyst coking. The latter phenomenon is also promoted by strong acidic sites. Such reaction environment allows in principle the use of diluted bioethanol mixtures. Therefore, in the present work we will investigate the unconventional use of a diluted ethanol solution (ca. 50 wt\%) for ethylene production. Such feedstock may be simply obtained by flash concentration of the fermentation broth, so limiting very much the ethanol purification costs [11,12].

In particular, we explored in detail the process conditions leading to ethanol dehydration to ethylene, also focusing on catalyst stability towards coking.

Different pathways have been proposed, according to which ethanol is directly dehydrated to ethylene (monomolecular reaction) or etherified to diethyl ether (bi-molecular path) $[13,14]$. The latter is considered a reaction intermediate leading to ethylene at relatively high temperature [15]. Commonly, when the reaction is carried out at $150-300^{\circ} \mathrm{C}$, diethyl ether is the main product. At higher temperature, ethylene selectivity increases, but it decays at temperature higher than $400-500^{\circ} \mathrm{C}$ due to formation of higher hydrocarbons and aromatics [2,16-19]. Many byproducts are reported, such as acetic acid, ethyl acetate, acetaldehyde, acetone, methanol, methane, propane, propylene, butane, butenes, hydrocarbons, carbon dioxide, carbon monoxide and hydrogen, besides possible coke formation by surface polymerisation of ethylene. Therefore, selectivity and durability issues are predominant over activity for this specific reaction.

Summaries of the catalytic performance of different zeolites have been reported $[2,14,20,21]$ and very recently reviewed by Sun and Wang [22]. Alumina is the most used and investigated catalyst for this application. However, besides coking problems, it suffers of competitive adsorption between ethanol and water. Therefore, the common strategy to add steam to prevent extensive deactivation induces significant drawbacks for catalytic 
activity. Zeolites have been suggested as alternative catalysts, but also in this case stability issues may arise due to coking and poor hydrothermal stability in the presence of steam.

We here selected BEA zeolite samples with tailored acidity. The BEA microporous structure is constituted by channels ca. $6.7 \AA$ in size, allowing the diffusion of ethanol with limited resistance [23], since almost all the accessible free volume of the pores is available based on the characteristic molecular size of ethanol (ca. $3.8 \AA$ ) [24]. The effect of both acidity of zeolite catalysts and reaction conditions has been considered to optimize the selectivity to ethylene. Ni addition has been also explored as a further way to tune process selectivity towards ethylene or syngas, according to the production scope. Indeed, $\mathrm{Ni}$ is active for the reforming of higher olefins and hydrocarbons, thus possibly improving catalyst selectivity to ethylene. Catalyst durability has been also taken into account. The prepared catalysts were characterized by various techniques and then tested for the production of ethylene under variable reaction conditions.

\section{2 - EXPERIMENTAL}

\section{1 - Catalyst preparation}

Catalysts characterized by different acidity and $\mathrm{Ni}$ loading were prepared. Tetraethylammonium BEA (TEABEA) zeolites with Si/Al ratio of 12.5 and $17(\mathrm{~mol} / \mathrm{mol})$ provided by RIPP (China) were calcined in air $\left(100^{\circ} \mathrm{C} / \mathrm{h}\right)$ at $550^{\circ} \mathrm{C}$ for $15 \mathrm{~h}$ under static conditions to remove the organic template. Both the organic-free BEA zeolites were then treated two times with $400 \mathrm{~mL}$ of $0.1 \mathrm{~mol} / \mathrm{L} \mathrm{NH}_{4} \mathrm{NO}_{3}$ solution during $3 \mathrm{~h}$ in order to exchange $\mathrm{K}^{+}$and $\mathrm{Na}^{+}$ions present in industrial BEA zeolite with $\mathrm{NH}_{4}{ }^{+}$ion. Then, the solids were washed with distilled water and dried overnight at $90^{\circ} \mathrm{C}$. The $\mathrm{NH}_{4} \mathrm{AIBEA}$ samples 
were calcined in air $\left(100^{\circ} \mathrm{C} / \mathrm{h}\right)$ for $3 \mathrm{~h}$ at $500^{\circ} \mathrm{C}$ under static conditions to remove $\mathrm{NH}_{3}$ and obtain the acidic form of the zeolite BEA, HAIBEA (I) and HAIBEA(II), with Si/AI ratio of 12.5 and $17(\mathrm{~mol} / \mathrm{mol})$, respectively.

The treatment of the TEABEA zeolites with $\mathrm{Si} / \mathrm{Al}$ ratio of 12.5 and $17(\mathrm{~mol} / \mathrm{mol})$ with nitric acid $(13 \mathrm{~mol} / \mathrm{L})$ at $80^{\circ} \mathrm{C}$ under stirring in air lead to removing of the organic template (TEA) and $\mathrm{Al}$ atoms. The treatment has been carried out for short $(0.08 \mathrm{~h}$, partial dealumination, HAISiBEA $(x)$ ) or prolonged time (4 h, deep dealumination, SiBEA $(x)$ ).

$\mathrm{Ni}$ was added by wet impregnation from a $\mathrm{Ni}\left(\mathrm{NO}_{3}\right)_{2} \cdot 6 \mathrm{H}_{2} \mathrm{O}$ solution. Proper amount of $\mathrm{Ni}$ precursor was dissolved in $200 \mathrm{~mL}$ water and the solid suspension was stirred for $24 \mathrm{~h}$ at room temperature at $\mathrm{pH}$ of 3.3. Then, the suspension was stirred in evaporator under vacuum of a water pump for $2 \mathrm{~h}$ in air at $60^{\circ} \mathrm{C}$ until the water was evaporated.

\section{2 - Catalyst characterisation}

X-ray powder diffraction (XRD) analysis was carried out at room temperature by means of a PHILIPS PW1830 diffractometer with Bragg-Brentano $\theta-2 \theta$ geometry. The CuK $\alpha$ radiation $(\lambda=1.5406 \AA)$ was used. Intensities were collected over a $21^{\circ}-90^{\circ} 2 \theta$ range with $0.03^{\circ}$ step size and $4 \mathrm{~s}$ step time. The apparatus was provided with graphite monochromator. The voltage and current intensity of the generator were set at $40 \mathrm{kV}$ and $30 \mathrm{~mA}$ respectively. The Rietveld method [25] was used for the XRPD data refinement using TOPAS software [26,27].

Specific surface area and pores size distribution were evaluated trough $\mathrm{N}_{2}$ adsorptiondesorption isotherms at $-196^{\circ} \mathrm{C}$ (Micromeritics, ASAP 2020). Surface area was calculated on the basis of the BET equation, whereas the pores size distribution was determined by 
the BJH method, applied to the $\mathrm{N}_{2}$ desorption branch of the isotherm. Micropores volume and area were determined from the t-plot analysis. Prior to the analysis the sample was outgassed at $300^{\circ} \mathrm{C}$ overnight.

${ }^{27} \mathrm{Al}$ MAS NMR spectra were recorded at $130.33 \mathrm{MHz}$ with a Bruker Avance 500 spectrometer with $1.3 \mu \mathrm{s}$ excitation pulse $(\pi / 6), 0.5 \mathrm{~s}$ for the recycle delay and 1024 accumulations. The spectra were acquired at a spinning rate of $12 \mathrm{kHz}$ in $4 \mathrm{~mm}$ (external diameter) zirconia rotor.

The Temperature Programmed Reduction (TPR) technique was employed to identify different metallic species possibly present in the catalysts according to the different reduction temperatures, in case used to assess the interaction strength between the active phase and the support. The catalyst was placed in a quartz reactor and heated from room temperature to $800^{\circ} \mathrm{C}$ by $10^{\circ} \mathrm{C} / \mathrm{min}$ in a $5 \% \mathrm{H}_{2} / \mathrm{Ar}$ mixed gas stream flowing at $40 \mathrm{~mL} / \mathrm{min}$. Temperature Programmed Oxidation (TPO) was carried out on the reduced sample by feeding $40 \mathrm{~mL} / \mathrm{min}$ of $10 \mathrm{vol} \% \mathrm{O}_{2} / \mathrm{He}$ gas mixture while heating by $10^{\circ} \mathrm{C} / \mathrm{min}$ from room temperature to $800^{\circ} \mathrm{C}$.

SEM images have been obtained using a Field Emission Gun Electron Scanning Microscopy LEO 1525, after metallization with Cr. Elemental composition was determined using a BrukerQuantax EDS.

TEM images have been obtained using a Philips 208 Transmission Electron Microscope. The samples were prepared by putting one drop of an ethanol dispersion of the catalysts on a copper grid pre-coated with a Formvar film and dried in air.

FT IR spectra have been recorded in static conditions by a Nicolet Nexus Fourier transform instrument, using conventional IR cells connected to a gas manipulation apparatus. Weighted pressed disks of pure catalyst powders $(30 \mathrm{mg})$ were activated by 
prolonged outgassing at $500^{\circ} \mathrm{C}$. Pyridine (py, Aldrich, pur. 98\%) adsorption experiments have been performed over the activated samples using a standard, reproducible procedure: the sample was contacted with 5 torr of py, then outgassed at first for 30 minutes at room temperature, and further stepwise at increasing temperature $(150,200$, 300,400 and $\left.500^{\circ} \mathrm{C}\right)$.

\subsection{Activity testing}

Details on the equipment for activity testing have been previously reported elsewhere [28,29]. Briefly, the catalysts (ca. $0.5 \mathrm{~g}, 0.15-0.25 \mathrm{~mm}$ particle size) were diluted $1: 3$ $(\mathrm{vol} / \mathrm{vol})$ with $\mathrm{SiC}$ of the same size. The void space of the reactor was filled with quartz beads, ca. $1 \mathrm{~mm}$ in size. The sample was activated in $50 \mathrm{~cm} 3 / \mathrm{min}$ of a $20 \% \mathrm{H}_{2} / \mathrm{N}_{2}$ gas mixture, while heating by $10^{\circ} \mathrm{C} / \mathrm{min}$ up to $800^{\circ} \mathrm{C}$ for $1 \mathrm{~h}$.

Activity testing was carried out by feeding $0.017 \mathrm{~cm}^{3} / \mathrm{min}$ of a $3: 1 \quad(\mathrm{~mol} / \mathrm{mol})$ $\mathrm{H}_{2} \mathrm{O}: \mathrm{CH}_{3} \mathrm{CH}_{2} \mathrm{OH}$ liquid mixture by means of a Hitachi, mod. L7100, HPLC pump, added with $56 \mathrm{~cm}^{3} / \mathrm{min}$ of $\mathrm{N}_{2}$, used as internal standard, and $174 \mathrm{~cm}^{3} / \mathrm{min}$ of He. Such dilution of the feed stream was calibrated so to keep the reactants mixture in the vapour phase even at zero conversion at the reactor outlet.

The activity tests were carried out at atmospheric pressure, GHSV $=2500 \mathrm{~h}^{-1}$ referred to the ethanol + water gaseous mixture $\left(76500 \mathrm{~h}^{-1}\right.$ including the inert gases flow rate), at $500^{\circ} \mathrm{C}$. Additional testing at much shorted contact time were carried out on the best performing catalyst.

The analysis of the out-flowing gas was carried out by GC analysis. The analytical system allows to quantify simultaneously $\mathrm{H}_{2}, \mathrm{CO}, \mathrm{CO}_{2}$, ethanol, ethane, ethylene, water, acetaldehyde, propane, propylene and higher hydrocarbons if needed. Repeated analyses 
of the effluent gas were carried out every hour and the whole duration of every test at each temperature was $8 \mathrm{~h}$. The raw data, expressed as $\mathrm{mol} / \mathrm{min}$ of each species outflowing from the reactor, averaged after 4-8 h-on-stream, have been elaborated as better detailed elsewhere [28].

\section{3 - RESULTS AND DISCUSSION}

3.1 - Textural, structural and morphological properties of the fresh catalysts

The list of samples prepared is reported in Table 1.

$\mathrm{N}_{2}$ adsorption-desorption evidenced the typical isotherms of microporous materials with an evident hysteresis. BET surface area ranged between 320 and $360 \mathrm{~m}^{2} / \mathrm{g}$ for every catalyst (Table S1), with a main contribution of micropores, without dependence on Ni loading and Al content.

The $\mathrm{Si} / \mathrm{Al}$ ratio of the samples increased as expected due to dealumination (Table 1). The very similar values obtained for Si/Al ratio by EDX analysis for samples 2 and 3 treated upon different time by concentrated nitric acid solution is probably related with the fact that this analysis is averaged on different spots and in some cases (at the lowest Al content) the standard deviation is much higher than for the samples with higher amount of Al. To control better the reproducibility of the treatment the dealumination should be done using lower concentration of nitric acid solution and longer time of treatment.

XRD analysis (Fig. S1 in Supporting Information) coupled with Rietveld refinement evidenced the contemporaneous presence of the A, B and C polymorphs of BEA zeolite. The A-phase was always the most abundant (46-56 wt\%), followed by the B and C polymorphs (25-30\% and $20-25 \%$, respectively) [30]. No correlation between phase 
composition and sample treatment, dealumination and $\mathrm{Ni}$ loading was evidenced. The Ni loading was too low to give rise to reflections in the XRD patterns.

${ }^{27} \mathrm{Al}$ MAS NMR spectroscopy is known [31-33] as an efficient probe to determine the coordination and local structure of specific aluminium species in zeolite materials. Both tetrahedral and octahedral Al species can be easily distinguished based on their different chemical shifts. A position of Al resonance gives a good indication of the local environment of the aluminium site. For example, framework aluminum atoms in tetrahedral coordination $\left(\mathrm{Al}_{\mathrm{Td}}\right)$ exhibit a signal at 50-60 ppm while extraframework aluminum atoms in octahedral coordination (AlOh) usually give a signal at $\sim 0 \mathrm{ppm}$. The synergy between Brønsted and Lewis sites and the effect of dealumination on HY zeolites has been also evidenced by this technique [34,35].

Figure S2 shows the ${ }^{27} \mathrm{Al}$ MAS NMR spectra of $\mathrm{HAIBEA}(\mathrm{II})(\mathrm{Si} / \mathrm{Al}=14.5 \mathrm{~mol} / \mathrm{mol}$, EDX), HAIBEA(I) $(\mathrm{Si} / \mathrm{Al}=13.6 \mathrm{~mol} / \mathrm{mol}, \mathrm{EDX}), \mathrm{HAISiBEA}(\mathrm{II})(\mathrm{Si} / \mathrm{Al}=86 \mathrm{~mol} / \mathrm{mol}, \mathrm{EDX})$, $\operatorname{SiBEA}(\mathrm{I})(\mathrm{Si} / \mathrm{Al}=150 \mathrm{~mol} / \mathrm{mol}, \mathrm{EDX})$, and $\operatorname{SiBEA}(\mathrm{II})(\mathrm{Si} / \mathrm{Al}=111 \mathrm{~mol} / \mathrm{mol}, \mathrm{EDX})$ supports used for preparation of Ni-containing BEA zeolite catalysts. The two former supports were obtained by calcinations of TEABEA at $823 \mathrm{~K}$ for $15 \mathrm{~h}$ which led to much higher amount of tetrahedral (peaks at 56.9 and 54.0-53.6 ppm) and octahedral (peak at about of $0.0 \mathrm{ppm}$ ) species for HAIBEA(II), HAIBEA(I) and HAISiBEA(II) than for SiBEA(I) and SiBEA(II) treated with nitric acid for $4 \mathrm{~h}$ at $353 \mathrm{~K}$. The two signals at 56.9 and 54.0-53.6 ppm suggest the presence of two kinds of $\mathrm{Al}_{\mathrm{Td}}$ sites in $\operatorname{HAIBEA}(\mathrm{II}), \operatorname{HAIBEA}(\mathrm{I})$ and $\operatorname{HAISiBEA}(\mathrm{II})$. The absence of the peak at 0.0 for $\operatorname{SiBEA}(\mathrm{I})$ and $\operatorname{SiBEA}(\mathrm{II})$ indicates removal of extraframework octahedral $\mathrm{Al}(\mathrm{III})$ from these zeolites upon nitric acid treatments. For the latter samples only very low amount of Al was present indicating that traces of aluminum were still present in deeply dealuminated $\operatorname{SiBEA}(\mathrm{I})$ and $\operatorname{SiBEA}(\mathrm{II})$ samples. 
Temperature programmed reduction-oxidation-reduction (TPR-TPO-TPR) cycles have been performed on every sample. Higher reduction temperature usually is ascribed to more dispersed $\mathrm{Ni}$ and to metal species more strongly interacting with the support. This can be a key point to prevent the formation of $C$ filaments over metal particles $[28,36-38]$. Indeed, it is known that big size Ni particles are more prone to the formation of carbon nanotubes than smaller ones [39-42] due to easier subsurface accumulation of carbide species in the case of big metal aisles. Thus, in order to obtain more stable catalysts towards coking, Ni should be dispersed as much as possible during preparation. Sintering should be also avoided by metal stabilization by the support and this can be effectively favoured by enhancing the metal-support interaction strength. Therefore, the comparison of TPR cycles can suggest not only the dispersion of $\mathrm{Ni}$ and its weak or strong interaction with the support, but also its possible modifications upon activation.

An example of the results for samples 5,6 and 7 , characterized by variable Ni loading, is reported in Fig. 1. The fresh samples (TPR1, Fig. 1a) evidenced markedly different peak profiles depending on Ni loading. Peak intensity as expected increased with Ni content, but a marked shift towards lower reduction temperature was also observed. Therefore, $\mathrm{Ni}$ dispersion and metal support interaction strength progressively decreased with increasing $\mathrm{Ni}$ loading in this samples set. This may not be the only effect, since the same samples are also characterized by different $\mathrm{Si} / \mathrm{Al}$ ratio, which is also correlated to variable dispersion for this set of samples, but to a much more limited extent.

The second TPR collected after oxidation of the reduced sample evidenced a very different behavior. A high temperature reduction peak appeared at $550-600^{\circ} \mathrm{C}$, which was attributed to the redispersion of $\mathrm{Ni}$ during the previous thermal treatments (simulating catalyst activation before testing). The formation of $\mathrm{Ni}$-silicates can be supposed, ending in $\mathrm{Ni}$ species more dispersed and strongly interacting with the support, as better detailed 
elsewhere [30]. This would limit the sintering expected after high temperature treatment. The same results were observed for samples 3,4,9.

When increasing the Al content, i.e. sample acidity, the reduction pattern was generally shifted to lower temperature, indicating a lower $\mathrm{Ni}$ dispersion. This means that increasing the Al content induced a weakening of the metal-support interaction. Furthermore, the redispersion phenomenon upon activation above outlined was favored at high Si/Al ratio (deep dealumination), as expected due to the formation of silicates, being much less evident for the calcined, more acidic, samples.

Based on these data, low $\mathrm{Ni}$ loading and high Si/Al ratio lead to higher dispersion and to stronger metal support interaction. This should be beneficial to improve catalyst resistance towards coking as extensively described in the literature [43-45].

\section{2 - FT IR investigation of zeolite acidity}

FT IR analysis was carried out to investigate the acidic character of the prepared catalysts [46-49]. In the hydroxyl region of the spectra, recorded after outgassing at $500^{\circ} \mathrm{C}$ (spectra not reported) several common features appear for samples 1 and 8 (calcined samples): terminal Si-OH groups, characterized by a band at $3740 \mathrm{~cm}^{-1}$; bridging Al-OH-Si groups, responsible for strong Brønsted acidity characterized by a weak band at $3610 \mathrm{~cm}^{-1}$; a quite broad absorption centred at $3670 \mathrm{~cm}^{-1}$ which could be assigned to another family of Al-OH groups, whose $\mathrm{Al}$ is at least partially connected to the BEA framework [46,50]. Isolated Al$\mathrm{OH}$ groups characterized by a FT IR band at $3785 \mathrm{~cm}^{-1}$ and due to extraframework (EF) $\mathrm{Al}$, were detected for sample 1, having the highest Al content. Indeed, Al can be part of the tetrahedral framework of the zeolite or be segregated in extraframework position, typically acting as Lewis acidic site if it is not removed. In Figure S3 we report the detail of the $\mathrm{OH}$ stretching region exemplified for sample 1. All these $\mathrm{OH}$ groups are affected by pyridine 
adsorption (see discussion below) and appear as negative bands in the subtraction spectra reported in the Supporting Information (Figure S3).

After dealumination the feature at $3610 \mathrm{~cm}^{-1}$ disappears, as a consequence of a progressive disappearance of Brønsted acidity, as confirmed by pyridine adsorption experiments (see below). This effect points out that the dealumination leads to the creation of vacant sites without modifying significantly the zeolite structure as testified by XRD data $[47,48]$. On the contrary, different dealumination methods, such as the solid state one proposed by Müller et al. [51] for this application, consisting in isomorphic substitution of aluminum with silicon, predominantly removed extraframework Al, leaving the framework Al sites substantially unaffected.

Pyridine, whose kinetic diameter is reported to be $0.533 \mathrm{~nm}$, can actually enter the main channels of the BEA structure therefore accessing the strongly acidic bridging OHs located within the channels, whose characteristic band indeed disappears after pyridine adsorption, confirming their full titration. The characterisation of BEA catalysts is indeed broadly addressed in the literature using Py, used even with smaller size pores, such as those characteristic of MFI zeolites $[50,52,53]$ and even if diffusional limitations can occur for the smallest pores, operation under static conditions with sufficient equilibration time should avoid this problem, as in the present case.

Pyridine adsorption at room temperature over sample 1 (Fig. 2) led to the detection of strongly adsorbed pyridine species coordinated over Lewis acidic sites, characterized by bands at 1622, $1607 \mathrm{~cm}^{-1}$ and $1447 \mathrm{~cm}^{-1}$ together with pyridinium ion, characterized by bands at 1636, 1547 and $1490 \mathrm{~cm}^{-1}$ due to the interaction with Brønsted acidic centres. Weakly H-bound pyridine was also detected, characterized by bands at 1597, 1580 and $1437 \mathrm{~cm}^{-1}[46]$.

The thermal evolution of these species has been reported in the same Fig. 2 from room temperature up to $500^{\circ} \mathrm{C}$, leading to the disappearance of the bands due to $\mathrm{H}$-bound 
pyridine $\left(1597 \mathrm{~cm}^{-1}\right)$ and better evidencing the components at $1622 \mathrm{~cm}^{-1}$ assigned to Py coordinated over Lewis acidic $\mathrm{Al}^{3+}$ ions, quite similar to those typical of alumina and silicaalumina and also frequently reported for zeolites having EF contributions [54]. The component at $1606 \mathrm{~cm}^{-1}$ could be assigned to pyridine coordinated on weaker sites and decreases quite quickly upon outgassing at increasing temperatures. Features due to adsorbed pyridine, although reduced in intensity and slightly shifted towards higher frequencies, can be detected up to $500^{\circ} \mathrm{C}$ pointing out the strength of the pyridine coordination over both Lewis and Brønsted surface sites.

In Fig. 3 (bottom) the spectra related to pyridine adsorption and outgassing over sample 8 are reported from room temperature to $500^{\circ} \mathrm{C}$. Spectra are completely consistent with those reported for sample 1, for instance bands due to Brønsted acidic sites are detected together with bands due to pyridine coordinated over Lewis acidic sites having different strength. On the other side, the overall intensity of the pyridine bands, compared for all samples in the subtraction spectra recorded after outgassing at $200^{\circ} \mathrm{C}$ is slightly reduced for sample 8 in comparison with spectra of catalyst 1, because of the absence of EF Al sites. Moreover, the relative intensities of bands typical of pyridinium ion and molecular coordinated pyridine (for instance bands at 1635 and $1620 \mathrm{~cm}^{-1}$ [54]) which is a rough indication of the acidic character of these zeolites, is slightly higher for sample 8 than sample 1. Pyridine adsorption and desorption by outgassing at increasing temperatures has also been performed over the partially and deeply dealuminated samples 2, 3 and 9, whose spectra are reported in Fig. 2 and 3 (top). As for samples 2 and 3 (Fig. 2, top, and Fig. 2, broken line), the main bands of the spectra are detected at $1595-97,1580 \mathrm{~cm}^{-1}$ and 1440-35 $\mathrm{cm}^{-1}$, readily disappearing after outgassing. These are assigned to weakly bound pyridine, possibly $\mathrm{H}$-bound to silanol, whose stretching peaks appear as negative bands in the subtraction spectra (not reported) [46]. Weak bands above $1600 \mathrm{~cm}^{-1}$, and around 
$1450 \mathrm{~cm}^{-1}$, still detectable after outgassing at increasing temperature are due to pyridine coordinated over Lewis acidic sites corresponding to residual Al.

The comparison with the spectrum of pyridine adsorbed over samples 1-3 evidenced that from sample 1 to sample 2 and 3 there is a decrease in the relative intensity of bands due to pyridinium ions (about 1545 and $1637 \mathrm{~cm}^{-1}$ ), which completely disappear in sample 3 . The analysis of subtraction spectra in the $\mathrm{OH}$ stretching region (Figure S3) shows a very weak negative band at $3606 \mathrm{~cm}^{-1}$, confirming the existence of residual acidic OHs. This effect is not anymore detected for sample 3, after deep dealumination. Moreover, from sample 1 to sample 2 the overall intensity of the pyridine bands (Lewis and Brønsted acidic sites) appears significantly reduced, suggesting the reduced acidity of zeolites.

Some Lewis acidity (i.e. bands above $1600 \mathrm{~cm}^{-1}$ and at $1455 \mathrm{~cm}^{-1}$ ) could still be detected in the dealuminated samples, in spite of the absence of EF Al atoms. This effect has been discussed by Phung et al. [54] for HY zeolite, in which Lewis acidity arises also from framework Al ions enlarging their coordination state.

Pyridine adsorption over sample 9 (Fig. 3, top) shows a very similar behaviour and no residual Brønsted acidity can be detected anymore.

In conclusion, FT IR experiments provide evidence of the extensive dealumination of samples 2,3 and 9, resulting in the removal of most of framework and extraframework $\mathrm{Al}$ ions and indeed in changes of the amount and the nature of acidic sites. In fact, over these samples Brønsted acidity disappears as well as the strongest Lewis sites.

\section{3 - Thermodynamic analysis}

Using water + ethanol mixtures for ethylene production may not be intuitive and the operating conditions should be properly checked. Therefore, at first, the products distribution expected from thermodynamics has been evaluated. The Aspen Plus ${ }^{\oplus}$ process simulation tool has been used, adopting both the predictive Soave-Redlich-Kwong (PSRK) 
thermodynamic package and the Non-Random-Two-Liquid (NRTL) model with Wilson mixing rules to model non-ideality in liquid phase, coupled with the SRK equation of state to model real gas phases. Both models gave rise to the same results.

Equilibrium composition has been evaluated by using a Gibb's reactor model. Different simulations were carried out, considering different populations of compounds, to demonstrate that a reliable prevision of the products distribution under different operating conditions strictly depends on the reactions set hypothesised during thermodynamic analysis. The full discussion on this point and the results of different simulations are reported in the Supplementary Information.

Really different products distributions are expected from thermodynamics, depending on the reactions set taken into consideration. If methane is considered in the products list, which is a well known product of ethanol decomposition, the results are reported in Fig. S6. The most stable species at low temperature result from ethanol decomposition, reforming products becoming predominant at higher temperature. Dehydration products showed negligible concentration over the whole temperature range, demonstrating that they are not the thermodynamically favoured compounds.

According to this analysis some important conclusions can be drawn. At first, expected products and their evolution with time should be carefully estimated by taking into account all the possible products and reactions, otherwise improper conclusions are drawn. Furthermore, even if the addition of water slightly unfavours ethanol conversion (with negligible effect on the selectivity to ethylene), it may help limiting coke formation (products of polycondensation, such as aromatics are substantially absent in thermodynamically derived products distribution).

Finally, if ethylene is the desired product, besides selecting proper operating conditions, the optimisation of catalyst selectivity should be done, to turn the reaction pathway towards thermodynamically less favourable routes, i.e. ethanol dehydration rather than 
decomposition. Therefore, materials and conditions must be selected to drive the reaction under kinetic regime and not under thermodynamic control. In this way it is possible to achieve the desired ethylene selectivity by using diluted bioethanol solutions, a much cheaper feedstock than dehydrated ethanol.

\section{4 - Significance of the process}

According to the above reported thermodynamic study and previous literature reports, we selected to cofeed water in relevant amount with respect to ethanol (water/ethanol $=3$ $\mathrm{mol} / \mathrm{mol}$ ) for different reasons. This composition corresponds to $\mathrm{ca}$. $50 \mathrm{wt} \%$ mixture, which can be easily obtained from a fermentation broth by flash separation [11]. This mixture has to be further rectified with huge costs if absolute ethanol is desired. Indeed, a typical purification train for a fermentation broth consists of a flash unit, which concentrates the solution to ca. $50 \mathrm{wt} \%$ ( $25 \mathrm{~mol} \%, 55 \mathrm{vol} \%$ ) ethanol, followed by rectification to the azeotrope (ca. 90 wt\%). Final dehydration can be accomplished by different routes, such as azeotropic distillation or adsorption in molecular sieves columns. Among these three dehydration steps, flash has negligible installation and operation costs with respect to the subsequent operations. Therefore, the possibility to use $50 \mathrm{wt} \%$ ethanol is particularly interesting, because this feed is sufficiently purified from minerals and heavier compounds, but its separation costs are minimal with respect to further anhydrification [11,12]. As a result, the $50 \mathrm{wt} \%$ feed contains ca. $0.3 \mathrm{wt} \%$ of different oxygenated compounds, including methanol and few ppm of inorganic compounds. In a biorefinery scenario, bioethanol is produced and transformed into chemicals locally. Thus, using a cheaper feedstock with high water content is more economically advantageous and environmentally sustainable.

On the other hand, one may argue that heating up the ethanol dehydration reactor when cofeeding water requires additional energy input to generate steam than vaporising pure ethanol. This is correct in principle, but in industrial application internal heat recovery is 
usually accomplished: spent steam can be used to preheat the diluted bioethanol feed, so vaporising most of water cofed with ethanol. This makes the use of diluted bioethanol streams overall advantageous considering the additional benefits (already discussed) of cofeeding water on catalyst selectivity and durability (vide supra et infra).

More in detail, in a typical reactor configuration the reactor output can be used to preheat the inlet (Fig. 4), so the condensation heat of excess steam is almost fully used to heat up the diluted bioethanol mixture, providing the latent heat to vaporise the excess water in the feed. This is even more sustainable due to the formation of additional water in the reactor during the ethanol dehydration, which makes available more steam at reactor outlet and hence increased heat is available. This also provides a very simple route for ethylene purification, since no other condensable byproducts are present in our case (at difference with most literature).

To quantify all these considerations, we calculated the heat input of the heater (Fig. $4 a$ ) to bring the feed $(0.25 \mathrm{kmol} / \mathrm{h}$ ethanol $+0.75 \mathrm{kmol} / \mathrm{h}$ water $)$ from $25^{\circ} \mathrm{C}$ to $500^{\circ} \mathrm{C}$. The reactor was operated at $500^{\circ} \mathrm{C}$ and completely converted ethanol to $0.25 \mathrm{kmol} / \mathrm{h}$ ethylene +1 $\mathrm{kmol} / \mathrm{h}$ water (the feed + reaction product), as in the case of our best catalyst (vide infra). The heat needed for dehydration in the reactor was also computed for completeness. The results are summarised in Table 2 . In the first case (base case, a) the reaction products were not used to preheat the feed.

Then, we modified the configuration as described in Fig. 4b: a heat exchanger was added for internal heat recovery, together with the original heater, which just accomplished final tuning to the desired reactor temperature. The net heat input was calculated as the sum of reactor + heater duties.

From these results one may easily observe that the duty to the heater fatally drops to 1 $\mathrm{kW}$, the reactor duty remaining the same. The majority of the heat needed to accomplish feed preheating (ca. $18 \mathrm{~kW}$ ) is internally exchanged by condensation of steam in the 
reactor outlet. This is more than 10 times lower than the value reported only for the azeotropic distillation with cyclohexane as reported e.g. by Bastidas et al. [55], so starting from the azeotrope and excluding the first rectification from the beer to the azeotrope.

Another possible observation may arise from the present operation at $500^{\circ} \mathrm{C}$ (coke free region) in comparison with different reports at temperature as low as $250-350^{\circ} \mathrm{C}$.

The duty for the reaction (case 3, Table 2) is quite the same, or even slightly higher actualising the calculation to the lower reaction temperature. Of course, the heat needed to achieve $300^{\circ} \mathrm{C}$ is lower, but this difference is computed in the recovery heat exchanger (lower heat needed, lower heat available for internal recovery). The net result is that the duty for the heater is $1.052 \mathrm{~kW}$ with respect to 1.081 at $500^{\circ} \mathrm{C}$ and the total net heat input is practically the same when working at 300 (case 3 ) or at $500^{\circ} \mathrm{C}$ (case 2).

In conclusion, according to a recent review [2] ethanol production and its future potential exceeds its exponentially increasing use as fuel, leaving room for a considerable improvement of its use as chemical. However, in order to propose a suitable alternative for existing, well conceived catalysts and optimised processes should be proposed. Braskem, Dow chemicals and Solvay produce bioethylene and polyethylene, but, in spite of the very low price of Brazilian bioethanol, the process is still not self-sustained without public incentives. In this view, the present investigation aims at designing new active and selective catalysts, able to convert a very much cheaper feedstock, to improve the economic sustainability of the process. The improvement of catalyst selectivity at $100 \%$ conversion with respect to the commercial alumina through the presently proposed zeolites and operating conditions can help from this point of view. Accordingly, catalyst durability should be of course checked for really prolonged time, but the use of this diluted feed and relatively high temperature help limiting coke formation. 
The ethanol conversion into ethylene is catalyzed by solid acids. Different mechanisms were proposed: i) ethanol is directly dehydrated to ethylene or ii) etherified to diethyl ether (DEE), that can be subsequently converted to ethylene. When the reaction is carried out at $150-300{ }^{\circ} \mathrm{C}, \mathrm{DEE}$ is a byproduct, but at higher temperature it is readily converted to ethylene. As recalled in the introduction, competing byproducts are acetic acid, ethyl acetate, acetaldehyde, acetone, methanol, methane, propane, propylene, butane, butenes, hydrocarbons, carbon dioxide, carbon monoxide and hydrogen [2]. Therefore, besides activity, a considerable selectivity improvement would enhance process sustainability by limiting the ethylene purification costs.

The following performances can be considered as benchmark. Alumina is the cheapest catalyst, but relatively high temperature $\left(450^{\circ} \mathrm{C}\right)$ is required and the ethylene yield is not particularly high (ca. 80\%) [20]. Different oxides were added to alumina to tune acidity and to improve selectivity, but much better results were achieved with zeolites, among which the most studied was ZSM-5 [56]. The same authors also tested Beta zeolites, but with very scarce results. Control of acidity (also by water addition in the feed) revealed a key factor.

The results of activity testing for samples with the same Ni loading (1.5 wt\%) and variable acidity is reported in Table 3 .

Full ethanol conversion was attained for every catalyst. As expected, the most acidic catalysts were more active for ethanol dehydration, leading to $>90 \%$ selectivity to ethylene. Decreasing catalyst acidity imparted higher activity for ethanol dehydrogenation to acetaldehyde and to steam reforming. The activity for the water gas shift reaction was also depressed by decreasing acidity, as testified by the higher $\mathrm{CO} / \mathrm{CO}_{2}$ molar ratio of sample 9. Carbon balance also increased with decreasing acidity due to lower coking rate. Dealumination has been proposed as a method to decrease not only acidity, but also hydrofilicity [51]. More hydrophobic samples were presented as more active for ethanol 
dehydration, since Al sites may competitively adsorb water and ethanol, so limiting activity. In the present case we did not observe any correlation of this kind.

The effect of Ni loading is presented in Table 4. The choice to add a metal phase is based on previous studies on products distribution at variable temperature. Increasing the operating temperature, together with water addition may improve catalyst life, although Phung et al. [18] observed decreasing ethylene selectivity at increasing temperature due to the formation of higher alkanes and olefins. Ni was therefore chosen as co-catalyst due to large availability, low cost with respect to noble metal competitors and high activity for the decomposition of the expected byproducts. The idea was to add this metal to improve the selectivity to ethylene, especially abating byproducts which may be uneasy to separate from ethylene when working at high temperature. $\mathrm{Ni}$ addition is helpful to prevent the formation of such compounds by favouring their reforming, so leading to a more interesting gaseous mixture, which is much easier to fractionate and purify than hydrocarbon/olefin mixtures. Indeed, in the present work no trace of higher hydrocarbons, nor of diethyl ether, has been observed. On the other hand, such a limited Ni loading prevents extensive reforming of the produced ethylene. A comparison with the bare zeolite HAIBEA(II) is also presented in Table 5, showing a higher selectivity to ethylene and higher carbon balance for the Ni-loaded sample than for the bare acidic catalyst.

Therefore, the increase of selectivity here achieved by adding very low metal loading is able to decrease sensitively the ethylene separation/purification costs. When full conversion and $100 \%$ selectivity is achieved, ethylene purification can be done by simple condensation of water (already achieved through the heat recovery exchanger reported in Fig. 4b).

The two series of catalysts prepared from different BEA native samples at variable $\mathrm{Ni}$ loading presented the same features. After deep dealumination the Si/Al ratio did not result exactly the same. However, from a practical point of view, the acidity of the samples did 
not change appreciably when passing from $\mathrm{Si} / \mathrm{Al}=86$ to 111 (see quantitative comparison of acidity in Fig. 5: samples 2 and 9 are identical), so that the performance variation can be essentially ascribed to the variation of $\mathrm{Ni}$ loading. When increasing $\mathrm{Ni}$ amount, a decreasing activity for ethanol dehydration was observed, with the contemporaneous increase of activity for steam reforming (non negligible productivity of $\mathrm{H}_{2}, \mathrm{CO}$ and $\mathrm{CO}_{2}$ ), ethanol decomposition (increasing selectivity to methane) and water gas shift (decreasing $\left.\mathrm{CO} / \mathrm{CO}_{2}\right)$. Carbon balance also decreased with increasing Ni loading.

Therefore, if the goal is ethylene production deep dealumination and high $\mathrm{Ni}$ loading should be avoided. Indeed, samples 4 and 5, characterised by the highest metal loading, were substantially active for ethanol dehydrogenation, decomposition and reforming, rather than for its dehydration.

FT IR analysis showed that the dealumination treatment induced a depression of both Brønsted and Lewis acidity, with consequent drop of selectivity to ethylene and decreased coking activity. A difference was noticed in selectivity to ethylene also between the two calcined, more acidic samples: sample 8 exhibited more stable and higher selectivity to ethylene than sample 1 (Fig. 6). Sample 8 was characterised by similar Brønsted acidity, but lower Lewis contribution than catalyst 1 and no EF Al sites. This confirms the effect of Lewis acidity for ethylene formation and for catalyst deactivation by coking [56]. Lewis acidity is needed to form ethylene, but excessively strong (likely EF) Lewis acidic sites should be avoided to protect from coking. Indeed, sample 1 showed lower selectivity to ethylene during the first h-on-stream with respect to sample 8 , likely due to coking on the most acidic Lewis sites. Selectivity to ethylene on sample 1 increased with time-on-stream due to rapid rule out of strongly acidic sites, however keeping lower plateau selectivity to ethylene with respect to sample 8 during the whole duration of the test. These results also imply much more limited role of Brønsted acidic sites on activity with respect to recent 
literature reports on similar materials, very likely due to the different reaction conditions $[13,17,21]$.

A comparison with $\gamma-\mathrm{Al}_{2} \mathrm{O}_{3}$ has been also carried out (Table 5). The Ni/BEA samples here tested were characterised by the same full ethanol conversion, but higher selectivity and carbon balance with respect to the bare alumina catalyst. A progressive decrease of selectivity has been also observed at high time on stream (4-8 h). The key problem for a low selectivity in the case of alumina is related to the low carbon balance, which is indicative of progressive coke accumulation over the sample, with deactivation occurring during time-on-stream. In this case the addition of $\mathrm{Ni}$ is not beneficial, since the loss of selectivity is intrinsically due to catalyst acidity (i.e. coking) rather than to the formation of different byproducts.

\section{6 - Effect of acidic sites nature}

By looking at the pertinent literature, the reasonably possible reaction mechanism is a concerted elimination (E2) due to the instability of a primary carbocation in the case of ethanol dehydration. Alternatively, a non direct "rake" mechanism was proposed, with an adsorbed ethoxide species dehydrogenated to a surface acetaldehyde, that undergoes enolization to a vinyl alkoxide and subsequent hydrodeoxygenation [57].

The effect of water is still under debate. Using raw bioethanol (ca. 10 wt \% ethanol in $\mathrm{H}_{2} \mathrm{O}$ ) was detrimental both in terms of conversion and selectivity for alumina and titania-based catalysts [22] and temperature higher than $420^{\circ} \mathrm{C}$ was suggested to remove the water effect [58-61]. Therefore, also the effect of temperature seems contradictory, depending on the selected feed. In the absence of water, temperature higher than $200^{\circ} \mathrm{C}$ depresses ethylene selectivity due to the formation of byproducts, whereas by cofeeding water temperature should be increased to avoid the decrease of activity and selectivity. The effect of acidity was as expected pivotal $[60,61]$ and water cofeeding was reported to 
effectively tune acidity towards Brønsted type. The latter is reported as particularly effective for the present application [22,62-64], whereas the present data and the mechanism proposed below deal with both types of acidity, i.e. Brønsted (likely formed in excess water and relatively low temperature) and Lewis sites (if dehydration occurs at equilibrium at high temperature even in the presence of excess water). A recent density functional theory study proposed that the Brønsted acids on the alumina surface are weak and therefore the adsorption of ethanol over these sites does not lead to any reaction. Therefore, the Lewis acid sites were considered active. Diethyl ether formation happens most probably by a $S_{n}{ }^{2}$ mechanism, by a nucleophilic attack of a free ethanol molecule at an ethanol molecule coordinated to the alumina surface [65].

Therefore, we compared more quantitatively Brønsted and Lewis acidity of calcined and dealuminated samples in Fig. 5 and their effect on catalyst performance. The two calcined samples were the most acidic, with higher band intensity for both Brønsted and Lewis contributions with respect to the partially dealuminated sample 2 and the totally dealuminated sample 9. Sample 1 (calcined and characterised by the lowest Si/Al ratio), had similar band intensity and acid strength, i.e. similar trend of band intensity vs. outgassing temperature, with respect to sample 8 (calcined with slightly higher Si/Al ratio). Lewis acidity was however higher for sample 1 than for sample 8 . The activity for ethanol dehydration was similar, but selectivity to ethylene and carbon balance were in average higher for sample 8 than sample 1 (Fig. 6). Partial dealumination (sample 2) led to the suppression of Brønsted acidity and to a substantial decrease of Lewis acidity. This in turn determined a slight decrease of selectivity to ethylene and an increase of $\mathrm{C}$ balance. Finally, deep dealumination (sample 9) induced further suppression of Lewis acidity also, with noticeable drop of the selectivity to ethylene. We can therefore attribute a major role to Lewis acidic sites related to the Al content for ethanol dehydration to ethylene, in 
agreement with some literature data [17]. Lower contribution can be ascribed to native Brønsted acidity. Extraframework Lewis sites can be also correlated with coking.

A recent work by Xin et al. [21] reported the stable geometries or ethoxy species, ethylene and dietyil ether, when adsorbed in the vicinity of Al Lewis sites in ZSM-5. The reaction mechanism relies on Brønsted acidic sites, which are also involved in dimer formation. The same sites are also at the basis of the mechanism proposed by Chiang et al. [13]. In the present work, diethyl ether was never observed, so a dimolecular reaction mechanism, introduced for ethanol dehydration on other materials can be excluded. We can interpret the mechanism of ethanol dehydration based on Al Lewis acidic sites as follows (Scheme $1)$.

Scheme 1: Possible path for ethanol dehydration through interaction with an Al Lewis acidic site.
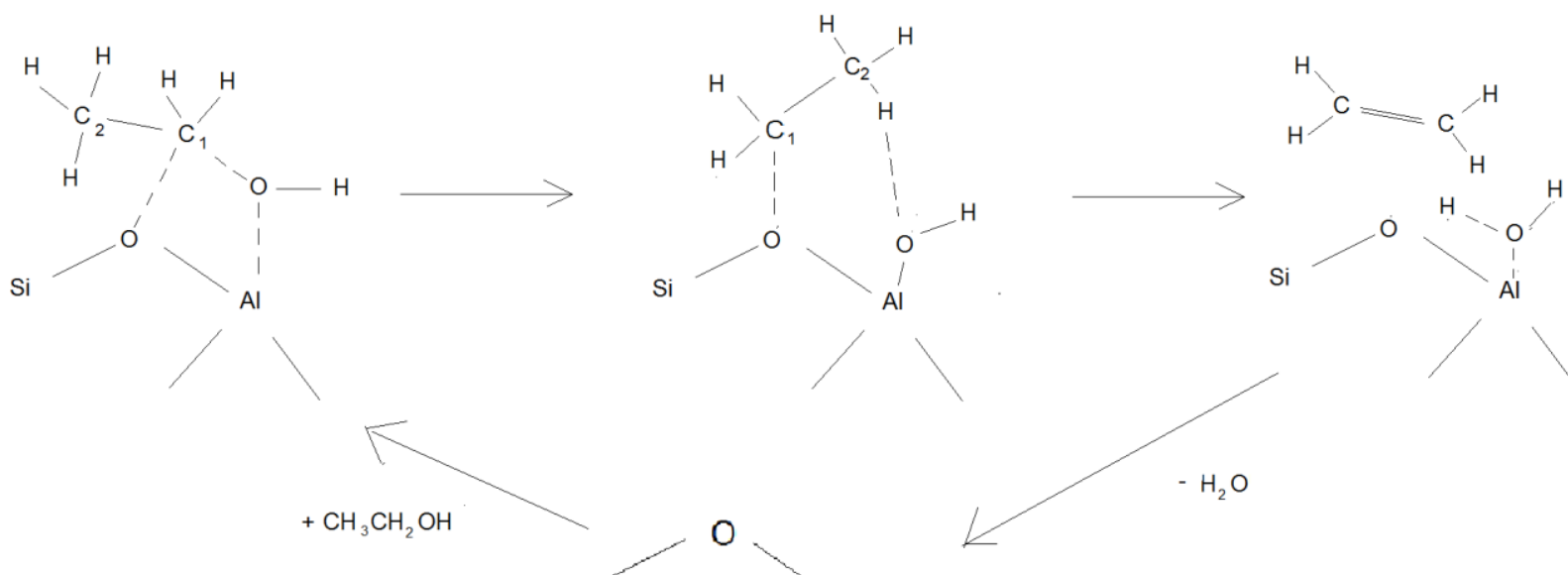

$\mathrm{Si}$

Al

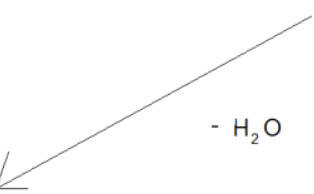

The AI Lewis acidic site can coordinate ethanol forming an ethoxy intermediate, which then evolves to ethylene and water, which desorbs. Water can compete with ethanol for adsorption on the Lewis acidic site, but in such case a Brønsted acidic site forms, which is 
involved in the mechanisms already very well detailed in the literature $[13,16,17,21]$. It should be mentioned that in such papers the attention is focused on the conditions that drive the possible parallel or consecutive steps towards diethyl ether. The latter forms when two adjacent sites are occupied by two adsorbed molecules of ethanol. In the present case, cofeeding water prevents significant selectivity to the dimer and higher alcohols by diluting the feed and thus competing with ethanol for adsorption.

The present results improve those reported in [17], which attributed intermediate activity to BEA-based catalysts, with selectivity problems at high conversion due to the formation of heavier by-products. The addition of small amounts of $\mathrm{Ni}$ and feed dilution allowed us to keep under control undesired heavier olefins without depressing selectivity to ethylene. Furthermore, Chiang et al. [13] discussed the ethanol dehydration mechanism over MFI, ferrierite and mordenite zeolites. The bimolecular pathway for ethylene formation through ethanol dimerization is allowed by bigger channel size in the case of mordenite, whereas it is forbidden for smallest pores. BEA catalysts have somehow bigger pores than mordenites, so the two reaction pathways (mono and bi-molecular dehydration) are expected to coexist. In the present case, selectivity to diethyl ether can be effectively suppressed in the presence of $\mathrm{Ni}$ and by operating at sufficiently high temperature while cofeeding water.

\section{7- Durability test}

Based on the interesting performance of sample 8 we tested it for 80 h-on-stream at $500^{\circ} \mathrm{C}$, water $/$ ethanol $=3: 1 \mathrm{~mol} / \mathrm{mol}$ after activation at $800^{\circ} \mathrm{C}$. Full ethanol conversion was maintained for the whole test, with average selectivity to ethylene $=99 \pm 3$. No evidence of by-products was observed, except some traces of $\mathrm{CO}$, hardly quantifiable. Carbon balance remained constantly $99 \pm 3$ without any evidence of catalyst deactivation during time-onstream (Fig. 7). 
The present BEA catalyst proved effective for this application when properly tuning surface acidity. Ethanol dehydration has been mostly studied over ZSM5 and alumina [66,67]. Alumina did not reach the same high selectivity as the present catalyst 8 and led to lower carbon balance. Poor stability has been observed for ZSM5 due to the presence of strong acidic sites, leading to heavy coking. Attempts to stabilise the catalyst with alkali additives were not effective. By contrast, by increasing pore size the residence time in the pores can be decreased, so improving catalyst life, as in the case of the present BEA catalysts $[68,69]$.

Additional testing at very high GHSV has been carried out on catalyst 8 (Table 5) in order to test selectivity below full conversion. This is not a trivial task when operating at high temperature due to the very high reactivity of ethanol. We tested the sample at $500^{\circ} \mathrm{C}$ in order to avoid lower temperature ranges which would likely induce different resistance to coking. Ethanol conversion was decreased by decreasing contact time (i.e. increasing the GHSV), but in order to lower conversion below $60 \%$ we were forced to apply dramatically high GHSV $=570,000 \mathrm{~h}^{-1}$, testifying the high activity of this sample.

At $53,000 \mathrm{~h}^{-1}$ ca. $70 \%$ ethanol conversion was observed, with decreasing ethylene selectivity (ca. 80\%), the only byproduct being acetaldehyde. Further increase of space velocity to $570,000 \mathrm{~h}^{-1}$ did not change the products observed (no further byproducts), but as expected the conversion decreased to ca. $20 \%$, with still decreasing selectivity to ethylene, down to ca. $65 \%$ (Table 5). No significant variation of the $\mathrm{C}$ balance was observed.

These data have an important mechanistic consequence, since they support the indirect mechanism of ethylene formation through acetaldehyde, that at very low contact time competitively desorbs before enolization and hydrodeoxygenation to the final product (vide supra). 
At last, comprehensive kinetic testing and modelling is presently in progress. Nevertheless, a very preliminary kinetic analysis was carried on the present tests at low conversion on catalyst 8 . The basic hypotheses were a first order reaction considering ethanol conversion in a plug flow reactor under ideal conditions. Integration of the rate equation allowed to derive a kinetic constant at $500^{\circ} \mathrm{C}$ equal to ca. $33 \mathrm{~s}^{-1}$.

\section{8-Characterisation of the spent catalysts}

FE-SEM and TEM micrographs have been collected on every spent sample and the most representative ones are reported in Fig. 8-10. Different coking contributions may be present. Catalyst acidity may induce the polymerisation of ethylene over the strongest acidic sites. Some $\mathrm{C}$ deposition can be also ascribed to the formation of $\mathrm{C}$ nanotubes over Ni. C balance was optimised by selecting proper operating conditions to avoid significant coke accumulation over the catalyst surface, also thanks to cofeeding water at relatively high temperature. Nevertheless, some samples exhibited significant deviation from 100\% C balance: samples 1, 4 and 5. For sample 1, the main contribution is expected to be correlated to its high acidity. However, by looking at Fig. 8 some carbon filaments may be noticed. Carbon nanotubes usually grow on big size Ni particles, which allow extensive subsurface carbide accumulation. TEM micrographs of the fresh catalyst 1 evidenced a lower $\mathrm{Ni}$ dispersion with respect to comparative samples with the same $\mathrm{Ni}$ loading. Furthermore, the TPR run carried out on the fresh sample 1 evidenced a weak metalsupport interaction, thus indicating the presence of $\mathrm{Ni}$ species more prone to sintering. This may explain the formation of some $\mathrm{C}$ nanofilaments.

When considering samples 4 and 5, however, by far more extensive coking revealed, due to carbon nanotubes formation (Fig. 9 and 10). Nanotubes were instead absent for catalysts with lower metal loading. Some Ni sintering was also evident for samples 4 and 5, with $\mathrm{Ni}$ particle size becoming poorly homogeneous up to $25 \mathrm{~nm}$. Thus, catalysts 
characterised by higher $\mathrm{Ni}$ loading and lower metal-support interaction strength, as demonstrated by TPR, are more prone to sintering and to form $\mathrm{C}$ filaments.

At last, no coking evidence was observed for sample 8 (Fig. 8 and 10), in spite of its prolonged use for $80 \mathrm{~h}$-on-stream.

\section{4 - CONCLUSIONS}

The possibility to use diluted ethanol streams for ethylene production has been demonstrated. This represents a much less expensive raw material with respect to anhydrous ethanol, providing a more economically and environmentally sustainable route for the production of an important building block. The effect of water cofeeding was explored both by means of thermodynamic analysis, process simulation and experimentally. We have found that particular care should be paid to the correct selection of possible coexisting products/reactions during thermodynamic analysis in order to predict reliable products distribution and to select accordingly the optimal reaction conditions.

BEA zeolites proved interesting catalysts for ethylene production by ethanol dehydration. The $\mathrm{Si} / \mathrm{Al}$ ratio and consequently catalyst acidity was the main parameter influencing catalyst selectivity to ethylene and durability, followed by Ni loading. Dealumination of the native zeolite depressed the selectivity to ethylene due to poor catalyst acidity, but care should be also paid to excessive Lewis acidity, mainly as EF sites, which may have a negative effect on the formation of coke and depress selectivity to ethylene.

Water cofeed and operation at relatively high temperature $\left(500^{\circ} \mathrm{C}\right)$ allowed full ethanol conversion very selectively to ethylene. Ni proved an effective co-catalyst to limit the production of heavier olefins, diethyl ether and hydrocarbons with respect to literature reports, although increasing $\mathrm{Ni}$ loading decreased the selectivity to ethylene by favoring the ethanol decomposition and/or reforming paths. Indeed, the decrease of contact time to lower conversion evidenced the coexistence of both reactions. Dehydration selectively led 
to ethylene at high contact time, whereas acetaldehyde and ethylene coexisted at very low contact time.

The comparison with an alumina benchmark evidenced better carbon balance and selectivity to ethylene of the present Ni-BEA samples.

Overall, a viable alternative with respect to commercial alumina is here proposed, which is able to improve the selectivity and productivity of ethylene. Substantially $100 \%$ yield can be achieved, making a very simple process that essentially separates excess water from ethylene. Excess water may help working in a coke free region, thus improving catalyst life, besides offering a really cheaper feedstock.

\section{REFERENCES}

[1] H. Zimmermann, R. Walzl, ., in: Ullmann's Encycl. Ind. Chem. Wiley-VCH Verlag GmbH Co., 2009.

[2] J.M.R. Gallo, J.M.C. Bueno, U. Schuchardt, Catalytic transformations of ethanol for biorefineries, J. Braz. Chem. Soc. 25 (2014) 2229-2243. doi:10.5935/01035053.20140272.

[3] S. Bastianoni, N. Marchettini, Ethanol production from biomass: Analysis of process efficiency and sustainability, Biomass Bioenergy. 11 (1996) 411-418.

[4] G. Huber, S. Iborra, A. Corma, Synthesis of transportation fuels from biomass: Chemistry, catalysts, and engineering, Chem. Rev. 106 (2006) 4044-4098.

[5] J. Althoff, K. Biesheuvel, A. De Kok, H. Pelt, M. Ruitenbeek, G. Spork, et al., Economic feasibility of the sugar beet-to-ethylene value chain, ChemSusChem. 6 (2013) 1625-1630. doi:10.1002/cssc.201300478.

[6] J.F. DeWilde, H. Chiang, D.A. Hickman, C.R. Ho, A. Bhan, Kinetics and mechanism of ethanol dehydration on $\mathrm{Y}$-Al 2O3: The critical role of dimer inhibition, ACS Catal. 3 (2013) 798.

[7] J. van Haveren, E.L. Scott, J. Sanders, Bulk chemicals from biomass, Biofuels Bioprod. Biorefin. 2 (2008) 41.

[8] S. Cosyn, K. Van der Woude, X. Sauvenier, J.N. Evrard, Sugar beet: A complement to sugar cane for sugar and ethanol production in tropical and subtropical areas, Int. Sugar J. 113 (2011) 120.

[9] S. Macrelli, J. Mogensen, G. Zacchi, Techno-economic evaluation of 2 nd generation bioethanol production from sugar cane bagasse and leaves integrated with the sugar-based ethanol process, Biotechnol. Biofuels. 5 (2012) 22.

[10] http://www.gruppomg.com/en/news/10, (n.d.). 
[11] I. Rossetti, J. Lasso, M. Compagnoni, G. De Guido, L. Pellegrini, H2 production from bioethanol and its use in fuel-cells, Chem. Eng. Trans. 43 (2015) 229-234. doi:10.3303/CET1543039.

[12] I. Rossetti, M. Compagnoni, G. De Guido, L. Pellegrini, G. Ramis, S. Dzwigaj, Ethylene production from diluted bioethanol solutions, Canad. J. Chem. Eng. in press (n.d.).

[13] H. Chiang, A. Bhan, Catalytic consequences of hydroxyl group location on the rate and mechanism of parallel dehydration reactions of ethanol over acidic zeolites, $\mathrm{J}$. Catal. 271 (2010) 251-261. doi:10.1016/j.jcat.2010.01.021.

[14] C. de las Pozas, R. Lopez-Cordero, J.A. Gonzalez-Morales, N. Travieso, R. RoqueMalherbe, Effect of pore diameter and acid strength in ethanol dehydration on molecular sieves, J. Mol. Catal. 83 (1993) 145-156. doi:10.1016/03045102(93)87015-Z.

[15] A. Morschbacker, Bio-ethanol based ethylene, Polym. Rev. 49 (2009) 79.

[16] T.K. Phung, G. Busca, Diethyl ether cracking and ethanol dehydration: Acid catalysis and reaction paths, Chem. Eng. J. 272 (2015) 92-101. doi:10.1016/j.cej.2015.03.008.

[17] T.K. Phung, L. Proietti Hernández, A. Lagazzo, G. Busca, Dehydration of ethanol over zeolites, silica alumina and alumina: Lewis acidity, Brønsted acidity and confinement effects, Appl. Catal. A Gen. 493 (2015) 77-89. doi:10.1016/j.apcata.2014.12.047.

[18] T.K. Phung, R. Radikapratama, G. Garbarino, A. Lagazzo, P. Riani, G. Busca, Tuning of product selectivity in the conversion of ethanol to hydrocarbons over $\mathrm{H}$ ZSM-5 based zeolite catalysts, Fuel Process. Technol. 3 (2015). doi:10.1016/j.fuproc.2015.03.012.

[19] K.K. Ramasamy, Y. Wang, Ethanol conversion to hydrocarbons on HZSM-5: Effect of reaction conditions and Si/Al ratio on the product distributions, Catal. Today. 237 (2014) 89-99. doi:10.1016/j.cattod.2014.02.044.

[20] M. Zhang, Y. Yu, Dehydration of ethanol to ethylene, Ind. Eng. Chem. Res. 52 (2013) 9505-9514. doi:10.1021/ie401157c.

[21] H. Xin, X. Li, Y. Fang, X. Yi, W. Hu, Y. Chu, et al., Catalytic dehydration of ethanol over post-treated ZSM-5 zeolites, J. Catal. 312 (2014) 204-215. doi:10.1016/j.jcat.2014.02.003.

[22] J. Sun, Y. Wang, Recent Advances in Catalytic Conversion of Glycerol, ACS Catal. 4 (2014) 1078-1090. doi:dx.doi.org/10.1021/cs4011343.

[23] T. Tago, H. Konno, S. Ikeda, S. Yamazaki, W. Ninomiya, Y. Nakasaka, et al., Selective production of isobutylene from acetone over alkali metal ion-exchanged BEA zeolites, Catal. Today. 164 (2011) 158-162. doi:10.1016/j.cattod.2010.10.034.

[24] E.L. First, C.E. Gounaris, J. Wei, C. a. Floudas, Computational characterization of zeolite porous networks: an automated approach, Phys. Chem. Chem. Phys. 13 (2011) 17339. doi:10.1039/c1cp21731c.

[25] H.M. Rietveld, A profile refinement method for nuclear and magnetic structures., J. Appl. Crystallogr. 2 (1969) $65-71$. 
[26] R.W. Cheary, A. Coelho, A fundamental parameters approach to X-ray line-profile fitting., J. Appl. Crystallogr. 25 (1992) $109-121$.

[27] R.W. Cheary, A.A. Coelho, J.P. Cline, Fundamental parameters line profile fitting in laboratory diffractometers, in: J. Res. Natl. Inst. Stand. Technol., 2004: pp. 1-25. http://www.scopus.com/inward/record.url?eid=2-s2.04043062870\&partnerID=tZOtx3y1.

[28] I. Rossetti, C. Biffi, C.L. Bianchi, V. Nichele, M. Signoretto, F. Menegazzo, et al., $\mathrm{Ni} / \mathrm{SiO} 2$ and $\mathrm{Ni} / \mathrm{ZrO} 2$ catalysts for the steam reforming of ethanol, Appl. Catal. B Environ. 117-118 (2012) 384-396. doi:10.1016/j.apcatb.2012.02.006.

[29] I. Rossetti, J. Lasso, V. Nichele, M. Signoretto, E. Finocchio, G. Ramis, et al., Silica and zirconia supported catalysts for the low-temperature ethanol steam reforming, Appl. Catal. B Environ. 150-151 (2014) 257-267. doi:10.1016/j.apcatb.2013.12.012.

[30] I. Rossetti, M. Compagnoni, E. Finocchio, G. Ramis, A. Di Michele, A. Zucchini, et al., Syngas production via steam reforming of bioethanol over Ni-BEA catalysts: A BTL strategy, Int. J. Hydrogen Energy. 41 (2016) 16878-16889. doi:10.1016/j.jhydene.2016.07.149.

[31] S. Moreno, G. Poncelet, Dealumination of small- and large-port mordenites: A comparative study, Micropor. Mater. 12 (1997) 197.

[32] T.H. Chen, K. Houthoofd, P.J. Grobet, Toward the aluminum coordination in dealuminated mordenite and amorphous silica-alumina: A high resolution 27AI MAS and MQ MAS NMR study, Micropor. Mesopor. Mater. 86 (2005) 31.

[33] R. Rachwalik, Z. Olejniczak, J. Jiao, J. Huang, M. Hunger, B. Sulikowski, Isomerization of $\alpha$-pinene over dealuminated ferrierite-type zeolites, J. Catal. 252 (2007) 161.

[34] Z. Yu, A. Zheng, Q. Wang, L. Chen, J. Xu, J.P. Amoureux, et al., Insights into the dealumination of zeolitehy revealed by sensitivity-enhanced 27AI DQ-MAS NMR spectroscopy at high field, Angew. Chemie - Int. Ed. 49 (2010) 8657-8661. doi:10.1002/anie.201004007.

[35] S. Li, A. Zheng, Y. Su, H. Zhang, L. Chen, J. Yang, et al., Brønsted / Lewis Acid Synergy in Dealuminated HY Zeolite: A Combined Solid-State NMR and Theoretical Calculation Study Brønsted / Lewis Acid Synergy in Dealuminated HY Zeolite : A Combined Solid-State NMR and Theoretical Calculation Study, J. Am. Chem. Soc. 129 (2007) 11161-11171. doi:10.1021/ja072767y.

[36] E. Finocchio, I. Rossetti, G. Ramis, Redox properties of Co- and Cu-based catalysts for the steam reforming of ethanol, Int. J. Hydrogen Energy. 38 (2013) 3213-3225.

[37] I. Rossetti, A. Gallo, V. Dal Santo, C.L. Bianchi, V. Nichele, M. Signoretto, et al., Nickel Catalysts Supported Over TiO 2 , SiO 2 and ZrO 2 for the Steam Reforming of Glycerol, ChemCatChem. 5 (2013) 294-306. doi:10.1002/cctc.201200481.

[38] V. Nichele, M. Signoretto, F. Menegazzo, I. Rossetti, G. Cruciani, Hydrogen production by ethanol steam reforming: Effect of the synthesis parameters on the activity of Ni/TiO2 catalysts, Int. J. Hydrogen Energy. 39 (2014) 4252-4258.

[39] G. Centi, S. Perathoner, Opportunities and prospects in the chemical recycling of carbon dioxide to fuels, Catal. Today. 148 (2009) 191-205.

doi:10.1016/j.cattod.2009.07.075. 
[40] V. Gonzalez De La Cruz, J. Holgado, R. Pereniguez, A. Caballero, Morphology changes induced by strong metal-support interaction on a Ni-ceria catalytic system, J. Catal. 257 (2008) 307-314. doi:10.1016/j.jcat.2008.05.009.

[41] K.O. Christensen, D. Chen, R. Lødeng, A. Holmen, Effect of supports and Ni crystal size on carbon formation and sintering during steam methane reforming, Appl. Catal. A Gen. 314 (2006) 9-22. doi:10.1016/j.apcata.2006.07.028.

[42] D. Chen, K. Christensen, E. Ochoa-Fernandez, Z. Yu, B. Totdal, N. Latorre, et al., Synthesis of carbon nanofibers: effects of $\mathrm{Ni}$ crystal size during methane decomposition, J. Catal. 229 (2005) 82-96. doi:10.1016/j.jcat.2004.10.017.

[43] V. Nichele, M. Signoretto, F. Pinna, F. Menegazzo, I. Rossetti, G. Cruciani, et al., $\mathrm{Ni} / \mathrm{ZrO} 2$ catalysts in ethanol steam reforming: Inhibition of coke formation by $\mathrm{CaO}-$ doping, Appl. Catal. B Environ. 150-151 (2014) 12-20. doi:10.1016/j.apcatb.2013.11.037.

[44] G. Ramis, I. Rossetti, E. Finocchio, M. Compagnoni, M. Signoretto, A.D. Michele, Metal dispersion and interaction with the supports in the coke production over ethanol steam reforming catalysts, 2015. doi:10.1007/978-3-319-16709-1_51.

[45] I. Rossetti, A. Gallo, V. DalSanto, C.L. Bianchi, V. Nichele, M. Signoretto, et al., Nickel Catalysts Supported Over TiO2, $\mathrm{SiO} 2$ and $\mathrm{ZrO} 2$ for the Steam Reforming of Glycerol, ChemCatChem. 5 (2013) 294-306. doi:10.1002/cctc.201200481.

[46] M. Trombetta, G. Busca, L. Storaro, M. Lenarda, M. Casagrande, A. Zambon, Surface acidity modifications induced by thermal treatments and acid leaching on microcrystalline H-BEA zeolite. A FTIR, XRD and MAS-NMR study, Phys. Chem. Chem. Phys. 2 (2000) 3529-3537.

[47] J.P. Marques, I. Gener, P. Ayrault, J.C. Bordado, J.M. Lopes, F.. Ramôa Ribeiro, et al., Infrared spectroscopic study of the acid properties of dealuminated BEA zeolites, Microporous Mesoporous Mater. 60 (2003) 251-262.

[48] A. Simon-Masseron, J.P. Marques, J.M. Lopes, F. Ramôa Ribeiro, I. Gener, M. Guisnet, Influence of the Si/Al ratio and crystal size on the acidity and activity of HBEA zeolites, Appl. Catal. A Gen. 316 (2007) 75-82.

[49] R. Baran, Y. Millot, T. Onfroy, J.-M. Krafft, S. Dzwigaj, Influence of the nitric acid treatment on Al removal, framework composition and acidity of BEA zeolite investigated by XRD, FTIR and NMR, Microporous Mesoporous Mater. 163 (2012) 122-130.

[50] K. Hadjiivanov, Identification and Characterization of Surface Hydroxyl Groups by Infrared Spectroscopy, Adv. Catal. 57 (2014) 99-318. doi:10.1016/B978-0-12800127-1.00002-3.

[51] J.M. Müller, G.C. Mesquita, S.M. Franco, L.D. Borges, J.L. de Macedo, J. a. Dias, et al., Solid-state dealumination of zeolites for use as catalysts in alcohol dehydration, Microporous Mesoporous Mater. 204 (2015) 50-57. doi:10.1016/j.micromeso.2014.11.002.

[52] R. Hajjar, Y. Millot, P.P. Man, M. Che, S. Dzwigaj, Two kinds of framework Al sites studied in BEA zeolite by X-ray diffraction, Fourier Transform Infrared spectroscopy, NMR techniques, and V probe, J. Phys. Chem. C. 112 (2008) 20167-20175.

[53] A.J. Jones, R.T. Carr, S.I. Zones, E. Iglesia, Acid strength and solvation in catalysis 
by MFI zeolites and effects of the identity, concentration and location of framework heteroatoms, J. Catal. 312 (2014) 58.

[54] T.K. Phung, G. Busca, On the Lewis acidity of protonic zeolites, Appl. Catal. A Gen. 504 (2015) 151-157. doi:10.1016/j.apcata.2014.11.031.

[55] P.A. Bastidas, I.D. Gil, G. Rodriguez, Comparison of the main ethanol dehydration technologies through process simulation, 20th Eurpean Symp. Comput. Aided Process Eng. - ESCAPE20. (2010) 1-6.

[56] I. Takahara, M. Saito, M. Inaba, K. Murata, Dehydration of Ethanol into Ethylene over Solid Acid Catalysts, Catal. Letters. 105 (2005) 249-252. doi:10.1007/s10562005-8698-1.

[57] D. Li, P. Bui, H.Y. Zhao, S.T. Oyama, T. Dou, Z.H. Shen, Rake mechanism for the deoxygenation of ethanol over a supported Ni2P/SiO2 catalyst, J. Catal. 290 (2012) 1-12. doi:10.1016/j.jcat.2012.02.001.

[58] G. Chen, S. Li, F. Jiao, Q. Yuan, Catalytic dehydration of bioethanol to ethylene over $\mathrm{TiO} 2 / \mathrm{y}-\mathrm{Al} 2 \mathrm{O} 3$ catalysts in microchannel reactors, Catal. Today. 125 (2007) 111-119. doi:10.1016/j.cattod.2007.01.071.

[59] A.P. Kagyrmanova, V.A. Chumachenko, V.N. Korotkikh, V.N. Kashkin, A.S. Noskov, Catalytic dehydration of bioethanol to ethylene: Pilot-scale studies and process simulation, Chem. Eng. J. 176-177 (2011) 188-194. doi:10.1016/j.cej.2011.06.049.

[60] R. Le Van Mao, T.M. Nguyen, J. Yao, Conversion of ethanol in aqueous solution over ZSM-5 zeolites, Appl. Catal. 61 (1990) 161-173. doi:10.1016/S01669834(00)82141-7.

[61] T.M. Nguyen, R. Le Van Mao, Conversion of ethanol in aqueous solution over ZSM5 zeolites, Appl. Catal. 58 (1990) 119-129. doi:10.1016/S0166-9834(00)82282-4.

[62] C.B. Phillips, R. Datta, Production of Ethylene from Hydrous Ethanol on H-ZSM-5 under Mild Conditions, Ind. Eng. Chem. Res. 36 (1997) 4466-4475.

http://www.scopus.com/inward/record.url?eid=2-s2.00031272394\&partnerID=tZOtx3y1.

[63] V. V. Bokade, G.D. Yadav, Heteropolyacid supported on montmorillonite catalyst for dehydration of dilute bio-ethanol, Appl. Clay Sci. 53 (2011) 263-271. doi:10.1016/j.clay.2011.03.006.

[64] A.T. Aguayo, A.G. Gayubo, A. Atutxa, M. Olazar, J. Bilbao, Catalyst deactivation by coke in the transformation of aqueous ethanol into hydrocarbons. Kinetic modeling and acidity deterioration of the catalyst, Ind. Eng. Chem. Res. 41 (2002) 4216-4224. http://www.scopus.com/inward/record.url?eid=2-s2.00037151307\&partnerID=tZOtx3y1.

[65] M.A. Christiansen, G. Mpourmpakis, D.G. Vlachos, Density functional theorycomputed mechanisms of ethylene and diethyl ether formation from ethanol on gamma-Al2O3(100), ACS Catal. 3 (2013) 1965-1975. doi:10.1021/cs4002833.

[66] J.F. DeWilde, H. Chiang, D. a Hickman, C.R. Ho, A. Bhan, Kinetics and Mechanism of Ethanol Dehydration on gamma-Al2O3: The Critical Role of Dimer Inhibition, ACS Catal. 3 (2013) 798-807. doi:10.1021/cs400051k.

[67] T. Maihom, P. Khongpracha, J. Sirijaraensre, J. Limtrakul, Mechanistic studies on the transformation of ethanol into ethene over Fe-ZSM-5 zeolite, ChemPhysChem. 
14 (2013) 101-107. doi:10.1002/cphc.201200786.

[68] Q. Sheng, S. Guo, K. Ling, L. Zhao, Catalytic dehydration of ethanol to ethylene over alkali-treated HZSM-5 zeolites, J. Braz. Chem. Soc. 25 (2014) 1365-1371. doi:10.5935/0103-5053.20140118.

[69] Q. Sheng, K. Ling, Z. Li, L. Zhao, Effect of steam treatment on catalytic performance of HZSM-5 catalyst for ethanol dehydration to ethylene, Fuel Process. Technol. 110 (2013) 73-78. doi:10.1016/j.fuproc.2012.11.004.

\section{ACKNOWLEDGEMENTS}

The valuable help of Dr. Alessio Sozzi, Dr. Giacomo Mariani, Dr. Anna Dell'Angelo and Mr.

Pier Moimare is gratefully acknowledged. The work was partly supported by H2FC European Infrastructure Project (Integrating European Infrastructure to support science and development of Hydrogen and Fuel Cell Technologies towards European Strategy for Sustainable Competitive and Secure Energy), project reference 284522.

\section{TABLES}

Table 1: Nomenclature, preparation parameters and main physical-chemical properties of the samples prepared. Dealumination achieved with $\mathrm{HNO}_{3}$ for 0.08 or $4 \mathrm{~h}$, partial and deep, respectively.

\begin{tabular}{|c|c|c|c|c|c|}
\hline Sample & Code & $\begin{array}{l}\text { Initial } \mathrm{Si} / \mathrm{Al} \\
\text { (atom/atom) }\end{array}$ & Post-treatment & $\begin{array}{l}\mathrm{Ni} \\
\text { content } \\
\text { (wt\%) }\end{array}$ & $\begin{array}{l}\mathrm{Si} / \mathrm{Al} \\
\text { (mol/mol) } \\
\mathrm{EDX}\end{array}$ \\
\hline 1 & $\mathrm{Ni}_{1.5} \mathrm{HAIBEA}(\mathrm{I})$ & 12.5 & Calcination & 1.5 & $13.6 \pm 0.9$ \\
\hline 2 & $\mathrm{Ni}_{1.5} \mathrm{HAISiBEA}(\mathrm{II})$ & 17 & $\begin{array}{c}\text { Partial } \\
\text { dealumination }\end{array}$ & 1.5 & $86 \pm 16$ \\
\hline 3 & $\mathrm{Ni}_{0.6} \mathrm{SiBEA}(\mathrm{II})$ & 17 & $\begin{array}{c}\text { Deep } \\
\text { dealumination }\end{array}$ & 0.6 & $83 \pm 15$ \\
\hline 4 & $\mathrm{Ni}_{3.0} \mathrm{SiBEA}(\mathrm{II})$ & 17 & $\begin{array}{c}\text { Deep } \\
\text { dealumination }\end{array}$ & 3.0 & $73 \pm 40$ \\
\hline 5 & $\mathrm{Ni}_{4.0} \mathrm{SiBEA}(\mathrm{I})$ & 12.5 & $\begin{array}{c}\text { Deep } \\
\text { dealumination }\end{array}$ & 4.0 & $92 \pm 21$ \\
\hline 6 & $\mathrm{Ni}_{0.7} \mathrm{SiBEA}(\mathrm{I})$ & 12.5 & $\begin{array}{c}\text { Deep } \\
\text { dealumination }\end{array}$ & 0.7 & $150 \pm 46$ \\
\hline 7 & $\mathrm{Ni}_{1.0} \mathrm{SiBEA}(\mathrm{I})$ & 12.5 & $\begin{array}{c}\text { Deep } \\
\text { dealumination }\end{array}$ & 1.0 & $96 \pm 15$ \\
\hline 8 & $\mathrm{Ni}_{1.5} \mathrm{HAIBEA}(\mathrm{II})$ & 17 & Calcination & 1.5 & $14.5 \pm 1.3$ \\
\hline
\end{tabular}




\begin{tabular}{|c|c|c|c|c|c|}
\hline & & & & & \\
\hline 9 & $\mathrm{Ni}_{1.5} \mathrm{SiBEA}(\mathrm{II})$ & 17 & $\begin{array}{c}\text { Deep } \\
\text { dealumination }\end{array}$ & 1.5 & $111 \pm 14$ \\
\hline
\end{tabular}

Table 2: Quantification of heat duties depending on process configuration and reactor operating temperature.

\begin{tabular}{|c|c|c|c|c|c|}
\hline Case & Description & $\begin{array}{l}\text { Duty } \\
\text { Heater } \\
\text { (kW) }\end{array}$ & $\begin{array}{l}\text { Duty } \\
\text { Reactor } \\
(\mathbf{k W})\end{array}$ & $\begin{array}{l}\text { Internally } \\
\text { recovered } \\
\text { heat }(\mathbf{k W})\end{array}$ & $\begin{array}{l}\text { Total heat } \\
\text { input }(k W)\end{array}$ \\
\hline 1 & $\begin{array}{l}\text { No heat recovery, } \\
\text { reactor } 500^{\circ} \mathrm{C} \text { (Fig. } \\
4 \mathrm{a} \text { ) }\end{array}$ & 18.984 & 3.226 & - & 22.210 \\
\hline 2 & $\begin{array}{l}\text { Internal heat } \\
\text { recovery, reactor } \\
500^{\circ} \mathrm{C} \text { (Fig. 4b) }\end{array}$ & 1.081 & 3.226 & 17.900 & 4.307 \\
\hline 3 & $\begin{array}{l}\text { Internal heat } \\
\text { recovery, reactor } \\
300^{\circ} \mathrm{C} \text { (Fig. 4b) }\end{array}$ & 1.052 & 3.249 & 14.769 & 4.301 \\
\hline
\end{tabular}

Table 3: Results of activity testing at $500^{\circ} \mathrm{C}$ after activation at $800^{\circ} \mathrm{C}$, water/ethanol $=3: 1$ $\mathrm{mol} / \mathrm{mol}, \mathrm{GHSV}=2500 \mathrm{~h}^{-1}$. Effect of catalyst acidity. Data averaged after 4-8 h-on-stream.

\begin{tabular}{|c|c|c|c|c|}
\hline Sample & 1 & 8 & 2 & 9 \\
\hline $\mathrm{Si} / \mathrm{Al}$ & 13.6 & 14.5 & 86 & 111 \\
\hline Ni (wt\%) & 1.5 & 1.5 & 1.5 & 1.5 \\
\hline $\begin{array}{c}\text { Ethanol } \\
\text { conversion } \\
(\%)\end{array}$ & $100 \pm 0.00$ & $100 \pm 0.00$ & $100 \pm 0.00$ & $100 \pm 0.00$ \\
\hline C balance $(\%)$ & $93 \pm 3$ & $98 \pm 3$ & $102 \pm 3$ & $98 \pm 4$ \\
\hline $\mathrm{S} \mathrm{CH}_{2} \mathrm{CH}_{2}(\%)$ & $93 \pm 3$ & $99 \pm 3$ & $91 \pm 1$ & $66 \pm 3$ \\
\hline$\underset{(\%)}{\mathrm{S} \mathrm{CH}}$ & $0.00 \pm 0.00$ & $2 \pm 2$ & $3 \pm 2$ & $18 \pm 1$ \\
\hline $\mathrm{S} \mathrm{CH}_{4}(\%)$ & $0.00 \pm 0.00$ & $0.00 \pm 0.00$ & $0.00 \pm 0.00$ & $0.00 \pm 0.00$ \\
\hline $\begin{array}{c}\mathrm{CO} / \mathrm{CO}_{2} \\
(\mathrm{~mol} / \mathrm{mol})\end{array}$ & - & - & $1.22 \pm 0.09$ & $2.7 \pm 0.2$ \\
\hline
\end{tabular}


Table 4: Results of activity testing at $500^{\circ} \mathrm{C}$ after activation at $800^{\circ} \mathrm{C}$, water/ethanol $=3: 1$ $\mathrm{mol} / \mathrm{mol}, \mathrm{GHSV}=2500 \mathrm{~h}^{-1}$. Effect of Ni loading. Data averaged after 4-8 h-on-stream.

\begin{tabular}{|c|c|c|c|c|c|c|}
\hline Sample & 3 & 9 & 4 & 6 & 7 & 5 \\
\hline Si/Al & 83 & 111 & 73 & 150 & 96 & 92 \\
\hline $\mathrm{Ni}(w t \%)$ & 0.6 & 1.5 & 3.0 & 0.7 & 1.0 & 4.0 \\
\hline $\begin{array}{c}\text { Ethanol } \\
\text { conversion (\%) }\end{array}$ & $100 \pm 0.00$ & $100 \pm 0.00$ & $100 \pm 0.00$ & $100 \pm 0.00$ & $100 \pm 0.00$ & $100 \pm 0$ \\
\hline C balance (\%) & $105 \pm 3$ & $98 \pm 4$ & $95 \pm 3$ & $96 \pm 7$ & $98 \pm 6$ & $92 \pm$ \\
\hline $\mathrm{S} \mathrm{CH}_{2} \mathrm{CH}_{2}(\%)$ & $66 \pm 7$ & $66 \pm 3$ & $0.00 \pm 0.00$ & $77 \pm 10$ & $33 \pm 4$ & $0.00 \pm 0$ \\
\hline $\mathrm{S} \mathrm{CH} \mathrm{CHO}_{3}(\%)$ & $31 \pm 4$ & $18 \pm 1$ & $20 \pm 5$ & $16 \pm 3$ & $33 \pm 4$ & $15 \pm 2$ \\
\hline $\mathrm{S} \mathrm{CH}_{4}(\%)$ & $0.00 \pm 0.00$ & $0.00 \pm 0.00$ & $15.8 \pm 0.5$ & $0.00 \pm 0.00$ & $0.00 \pm 0.00$ & $17 \pm$ \\
\hline $\begin{array}{c}\mathrm{H}_{2} \text { productivity } \\
\left(\mathrm{mol} \mathrm{min}^{-1} \mathrm{~kg}_{\mathrm{cat}}{ }^{-1}\right)\end{array}$ & $0.00 \pm 0.00$ & $0.00 \pm 0.00$ & $0.52 \pm 0.02$ & $0.00 \pm 0.00$ & $0.00 \pm 0.00$ & $0.48 \pm 0$ \\
\hline $\mathrm{CO} / \mathrm{CO}_{2}(\mathrm{~mol} / \mathrm{mol})$ & - & $2.7 \pm 0.2$ & $0.9 \pm 0.1$ & & $2.0 \pm 0.2$ & $1.45 \pm 0$ \\
\hline
\end{tabular}

Table 5: Results of activity testing at $500^{\circ} \mathrm{C}$ after activation at $800^{\circ} \mathrm{C}$, water/ethanol $=3: 1$ $\mathrm{mol} / \mathrm{mol}, \mathrm{GHSV}=2500 \mathrm{~h}^{-1}$. Comparison with reference catalysts and different conditions. Data averaged after 4-8 h-on-stream.

\begin{tabular}{|c|c|c|c|c|c|}
\hline Sample & 8 & $\begin{array}{l}8(\mathrm{GHSV}= \\
\left.53,000 \mathrm{~h}^{-1}\right)\end{array}$ & $\begin{array}{c}8(\text { GHSV }= \\
\left.570,000 h^{-1}\right)\end{array}$ & HAIBEA(II) & $\gamma-\mathrm{Al}_{2} \mathrm{O}_{3}$ \\
\hline $\mathrm{Si} / \mathrm{Al}$ & 14.5 & 13.6 & 14.5 & 14.5 & - \\
\hline $\mathrm{Ni}(w t \%)$ & 1.5 & 1.5 & 1.5 & 0 & - \\
\hline $\begin{array}{c}\text { Ethanol } \\
\text { conversion } \\
(\%)\end{array}$ & $100 \pm 0.00$ & $71 \pm 4$ & $19 \pm 2$ & $100 \pm 0.00$ & $100 \pm 0.00$ \\
\hline C balance (\%) & $98 \pm 3$ & $105 \pm 6$ & $98 \pm 3$ & $96 \pm 8$ & $88 \pm 7$ \\
\hline $\mathrm{S} \mathrm{CH}_{2} \mathrm{CH}_{2}(\%)$ & $99 \pm 3$ & $82.7 \pm 1.0$ & $64 \pm 6$ & $89 \pm 5$ & $80 \pm 7$ \\
\hline $\begin{array}{c}\mathrm{S} \mathrm{CH}_{3} \mathrm{CHO} \\
(\%)\end{array}$ & $2 \pm 2$ & $15.8 \pm 0.9$ & $36 \pm 5$ & $2.96 \pm 0.17$ & $3.7 \pm 0.3$ \\
\hline $\mathrm{S} \mathrm{CH}_{4}(\%)$ & $0.00 \pm 0.00$ & - & - & $0.00 \pm 0.00$ & $0.87 \pm 0.15$ \\
\hline $\begin{array}{c}\mathrm{CO} / \mathrm{CO}_{2} \\
(\mathrm{~mol} / \mathrm{mol})\end{array}$ & & - & - & $\mathrm{CO}_{2}=0.31 \pm 0.09$ & - \\
\hline
\end{tabular}


Fig. 1: TPR pattern of selected samples: a) TPR pattern collected on the fresh sample; $b$ ) after the first TPR run and further oxidation at $800^{\circ} \mathrm{C}$ for $1 \mathrm{~h}$. Heating to $800^{\circ} \mathrm{C}$ by $10^{\circ} \mathrm{C} / \mathrm{min}$ in $40 \mathrm{~mL} / \mathrm{min}$ of a $5 \% \mathrm{H}_{2} / \mathrm{Ar}$ mixture.

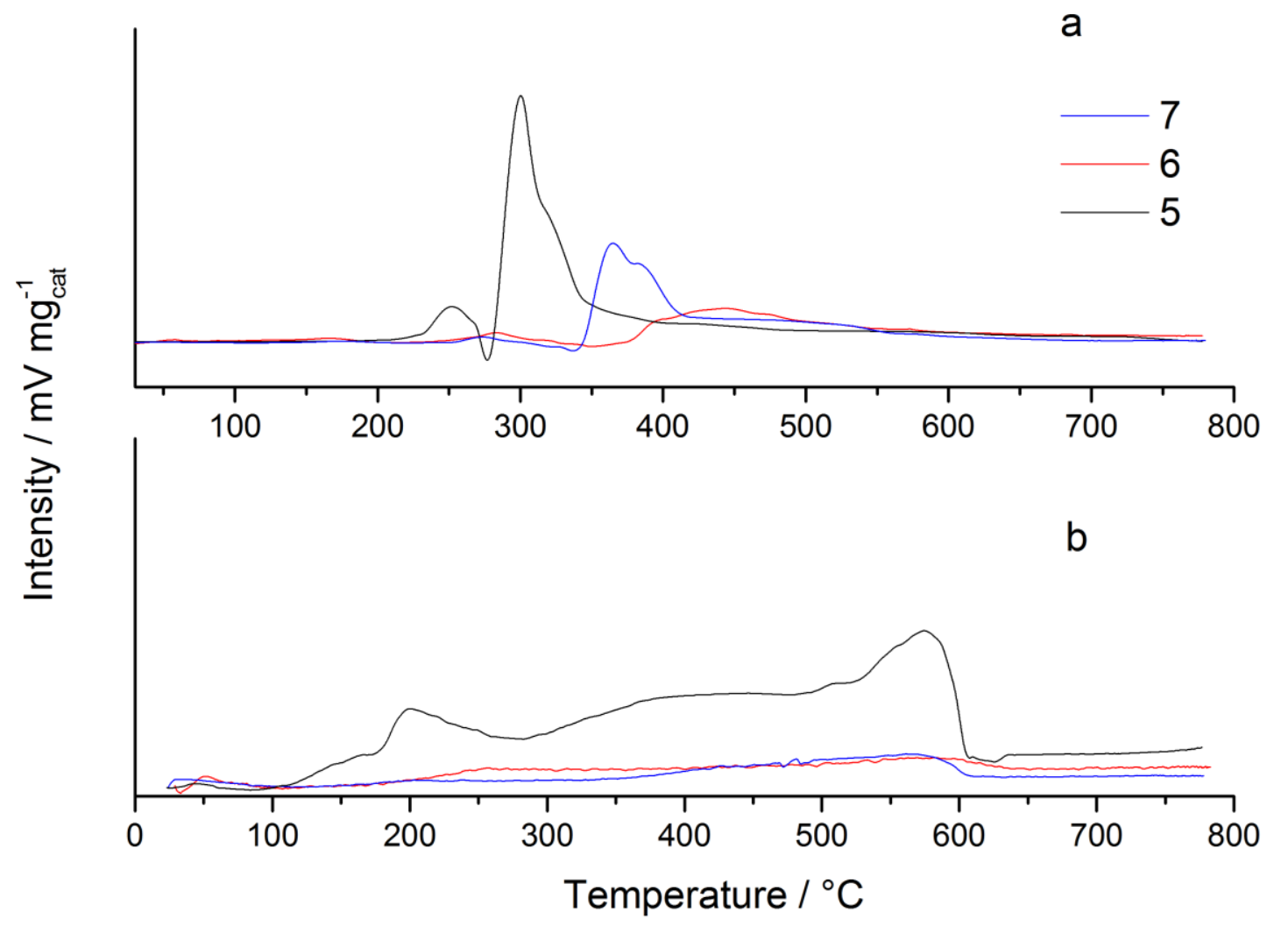


Fig. 2: FT IR subtraction spectra of the surface species arising from pyridine adsorption and desorption at increasing temperatures over samples 1 (bottom) and 2 (top). Spectrum of pyridine adsorption and desorption following prolonged outgassing at room temperature over sample 3 (broken line). Sample activation at $500^{\circ} \mathrm{C}$, saturation with 5 torr of py, outgassed for 30 minutes at r.t. and at increasing temperature $(150,200,300,400$ and $\left.500^{\circ} \mathrm{C}\right)$.

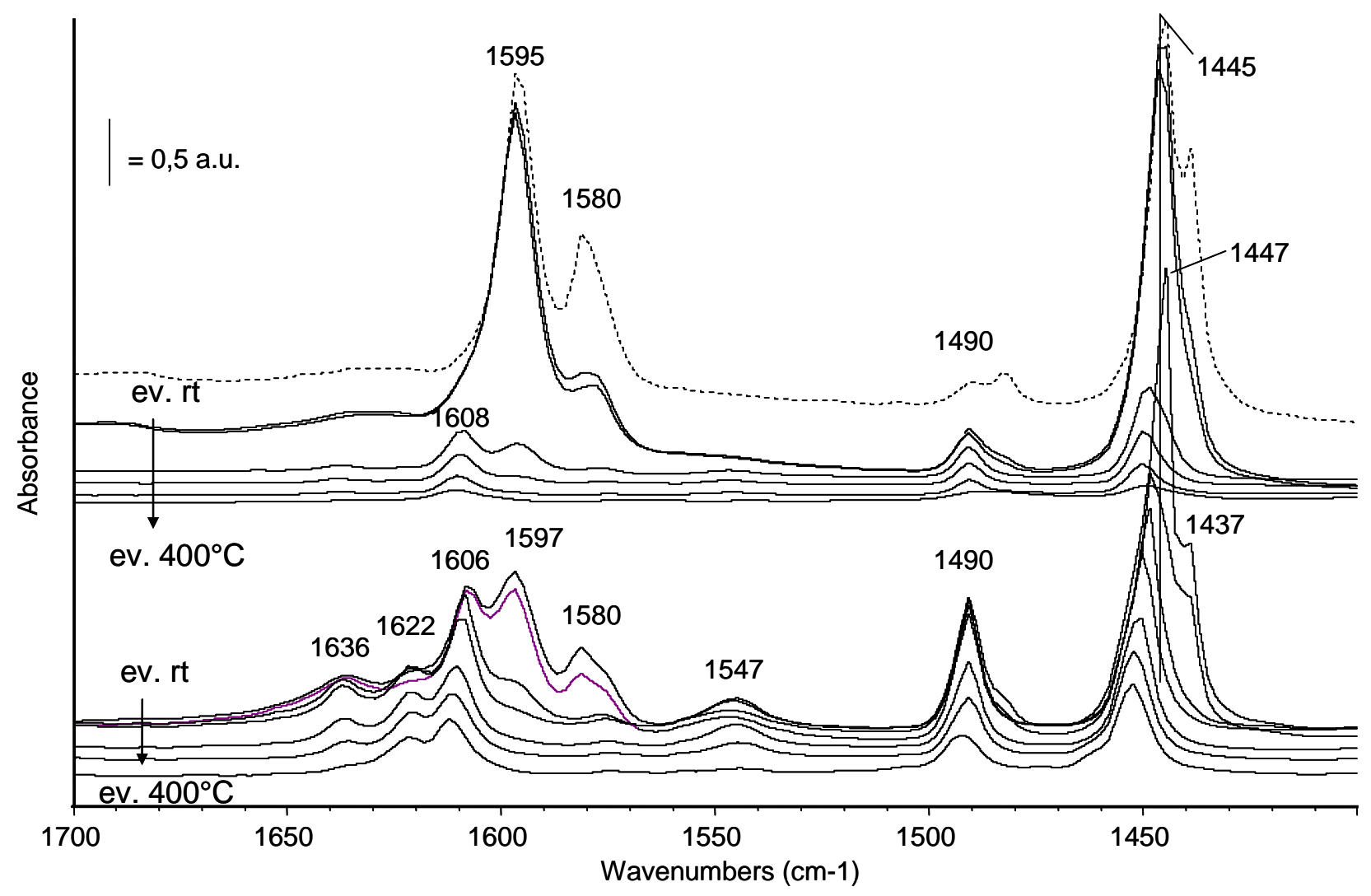


Fig. 3: FT IR subtraction spectra of the surface species arising from pyridine adsorption and desorption at increasing temperatures over samples 8 (bottom) and 9 (top). Sample activation at $500^{\circ} \mathrm{C}$, saturation with 5 torr of py, outgassed for 30 minutes at r.t. and at increasing temperature $\left(150,200,300,400\right.$ and $\left.500^{\circ} \mathrm{C}\right)$.

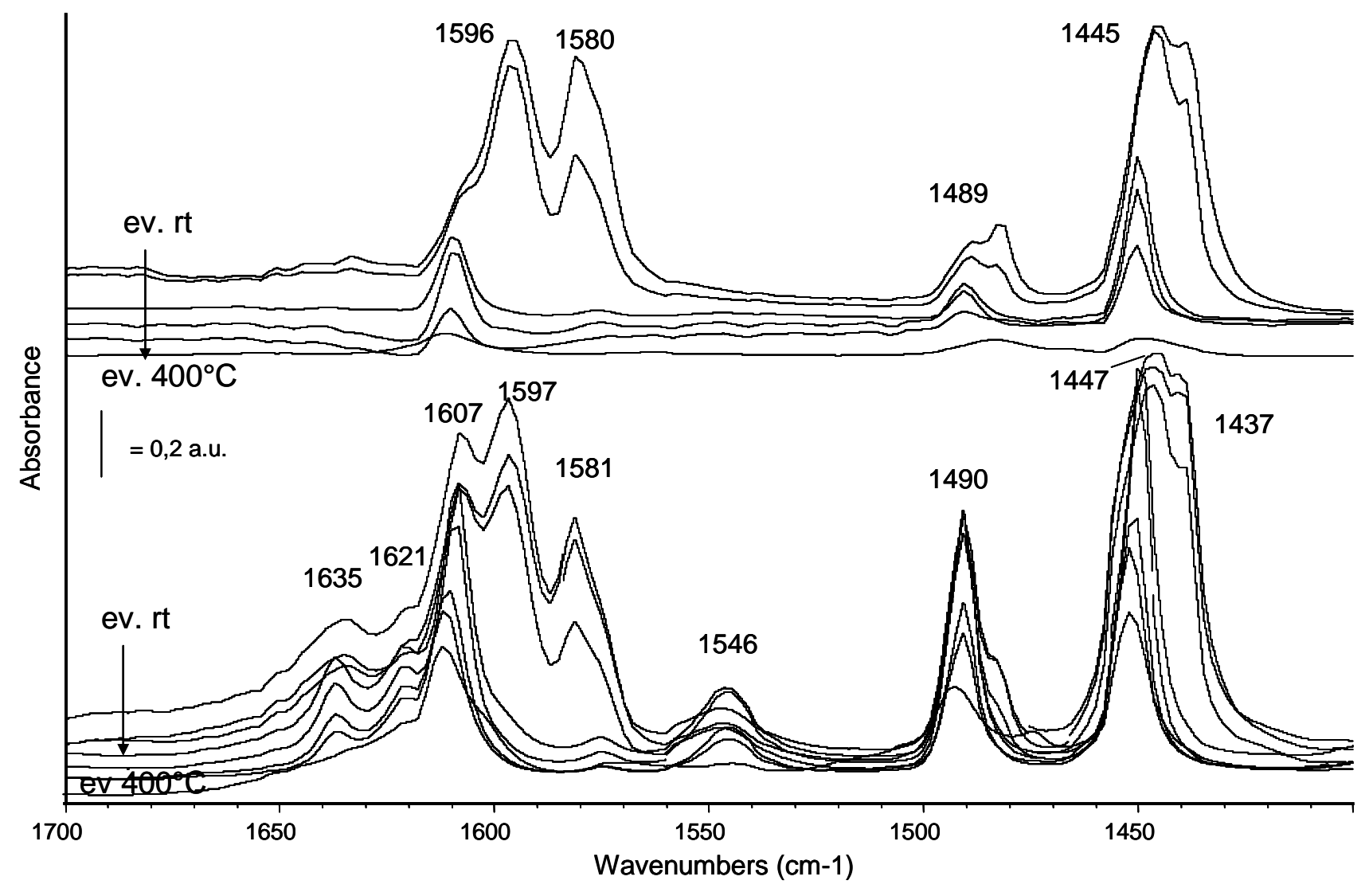


Fig. 4: Sketch of the reactor and heating devices (a) in the base case without internal heat recovery or (b) with a recovery heat exchanger.

a) Base case, no internal heat recovery

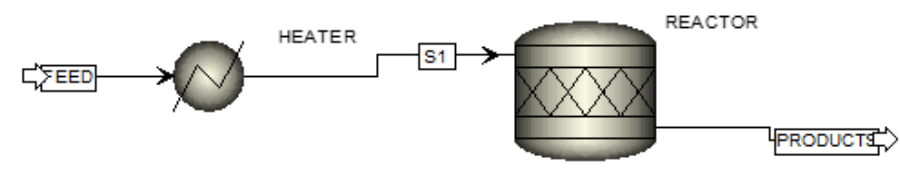

b) Internal heat recovery

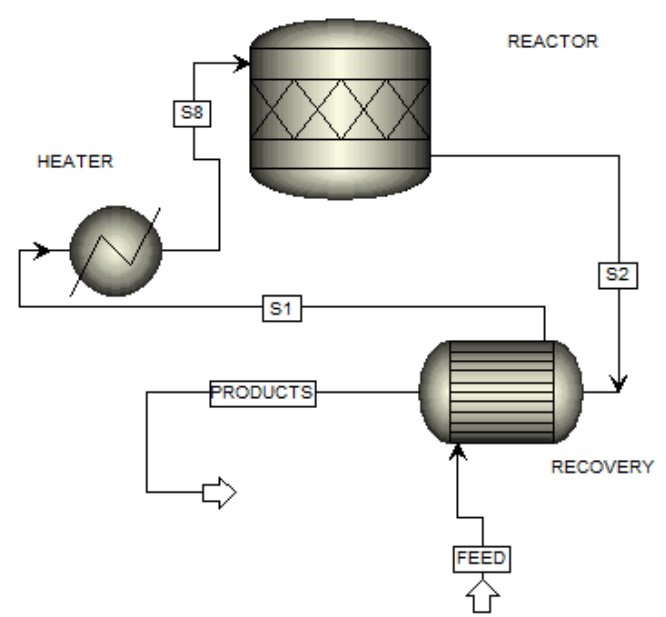

Fig. 5: Net intensity of FTIR bands attributed to pyridine adsorbed over Brønsted (1546 $\left.\mathrm{cm}^{-1}\right)$ and Lewis $\left(1450 \mathrm{~cm}^{-1}\right)$ acid sites as a function of Si/Al ratio and outgassing temperature after adsorption of pyridine at r.t. .

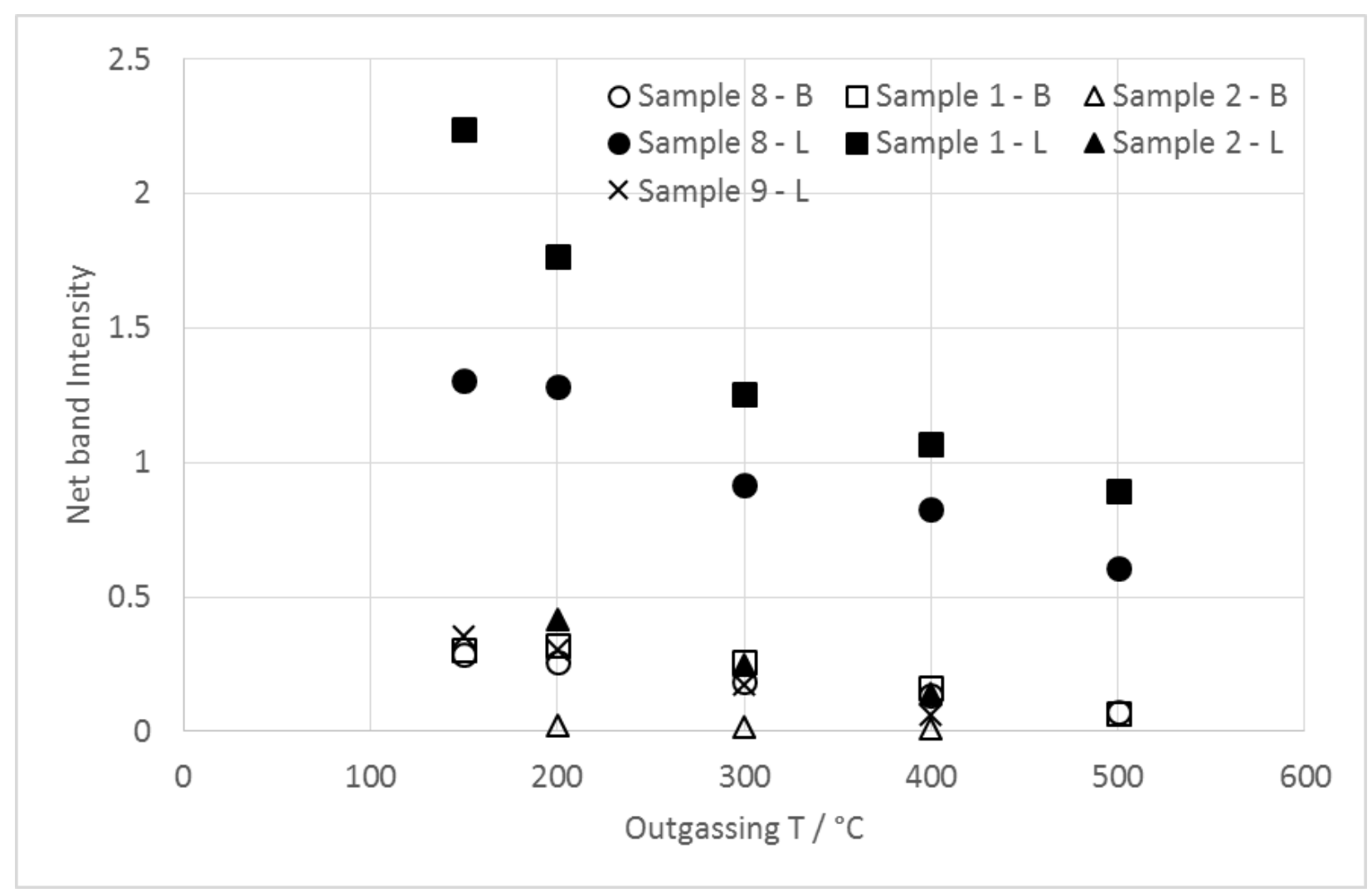


Fig. 6: Selectivity to ethylene vs. time-on-stream at $100 \%$ ethanol conversion, $500^{\circ} \mathrm{C}$, $\mathrm{GHSV}=2500 \mathrm{~h}^{-1}$ for samples 1 and 8 .

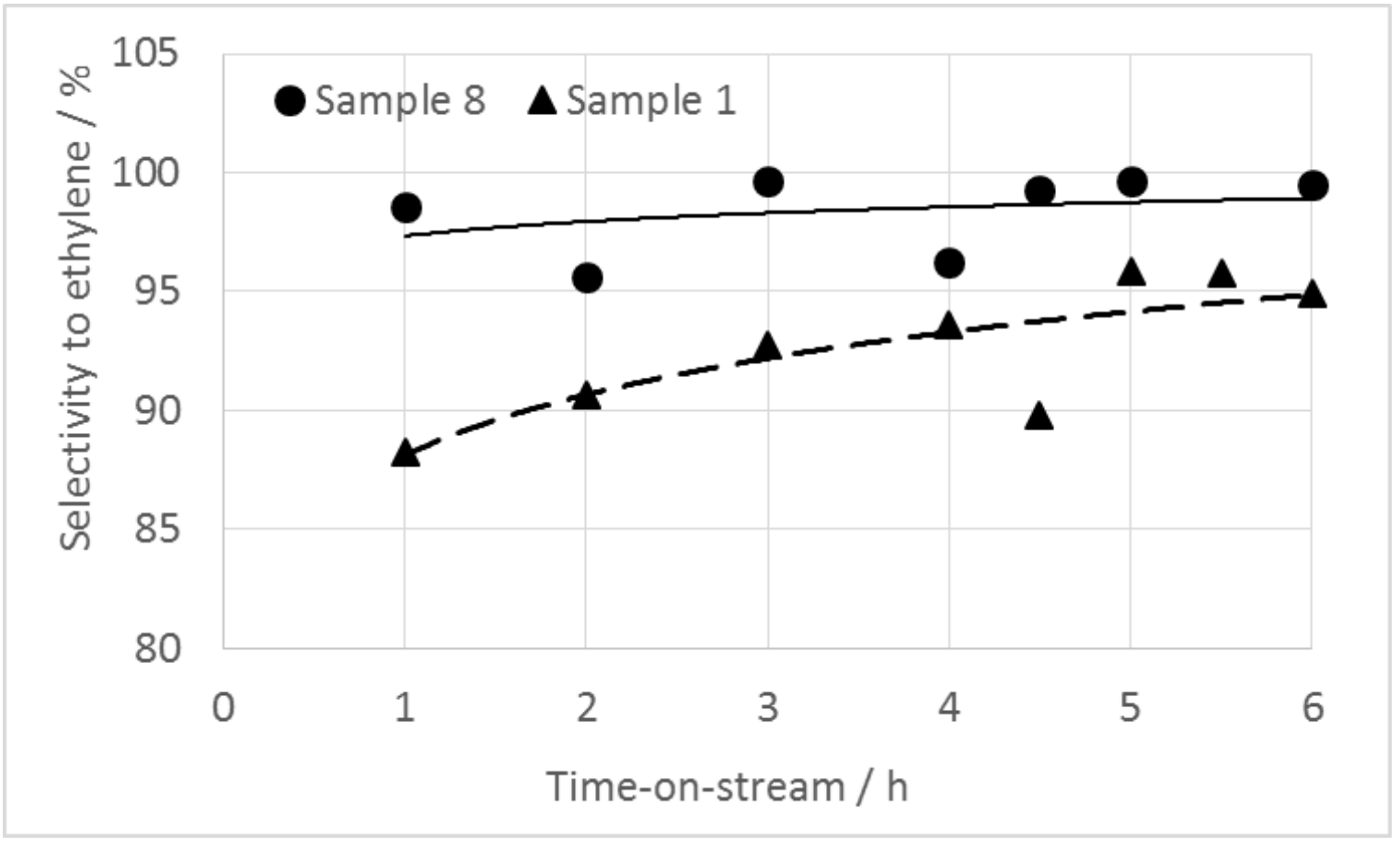

Fig. 7: Durability test for sample 8 , selectivity to ethylene vs. time-on-stream at $100 \%$ ethanol conversion, $500^{\circ} \mathrm{C}$, GHSV $=2500 \mathrm{~h}^{-1}$.

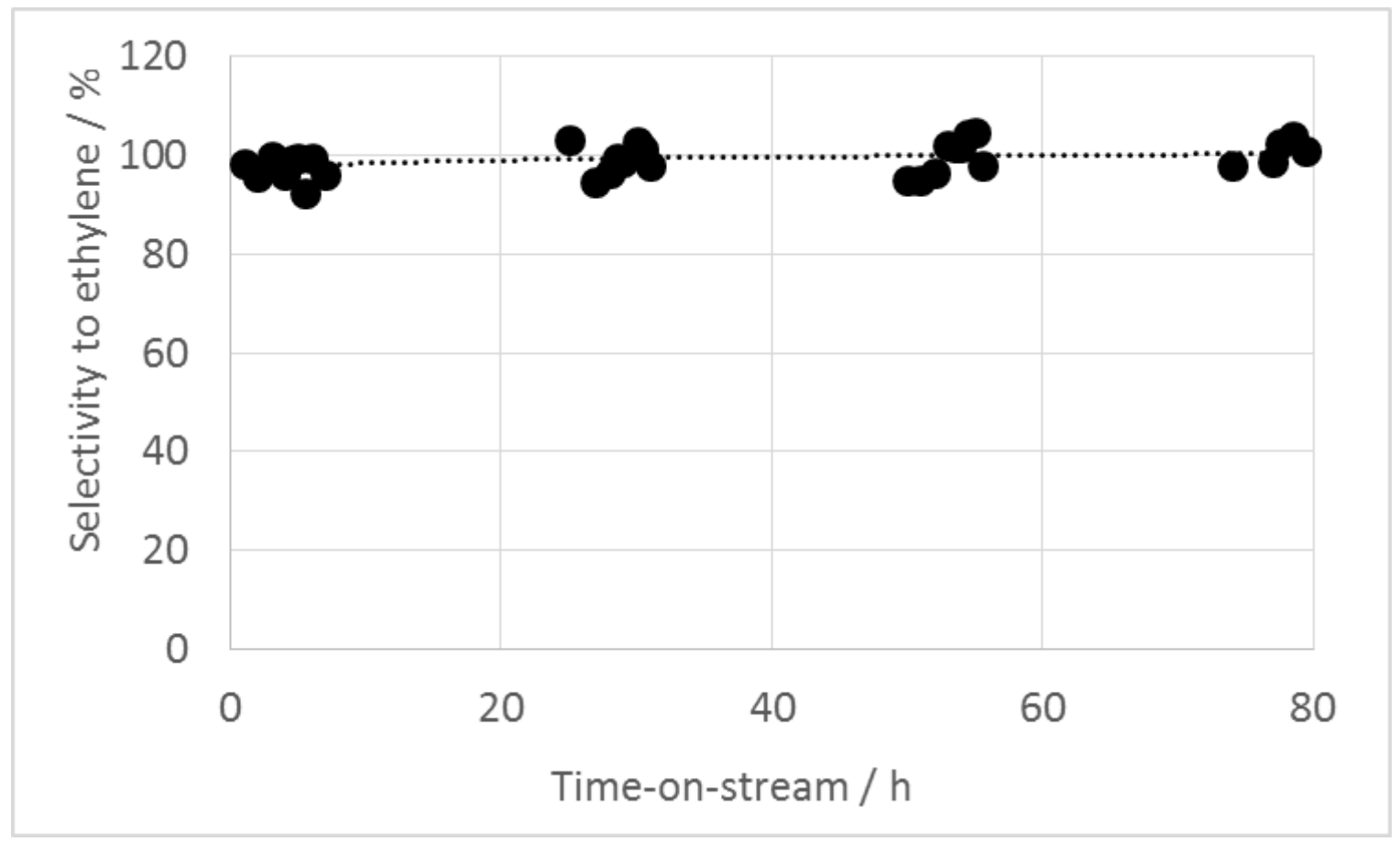


Fig. 8: FE-SEM micrographs of selected spent samples. Sample codes are reported in the relative pictures. Marker size $=200 \mathrm{~nm}$.

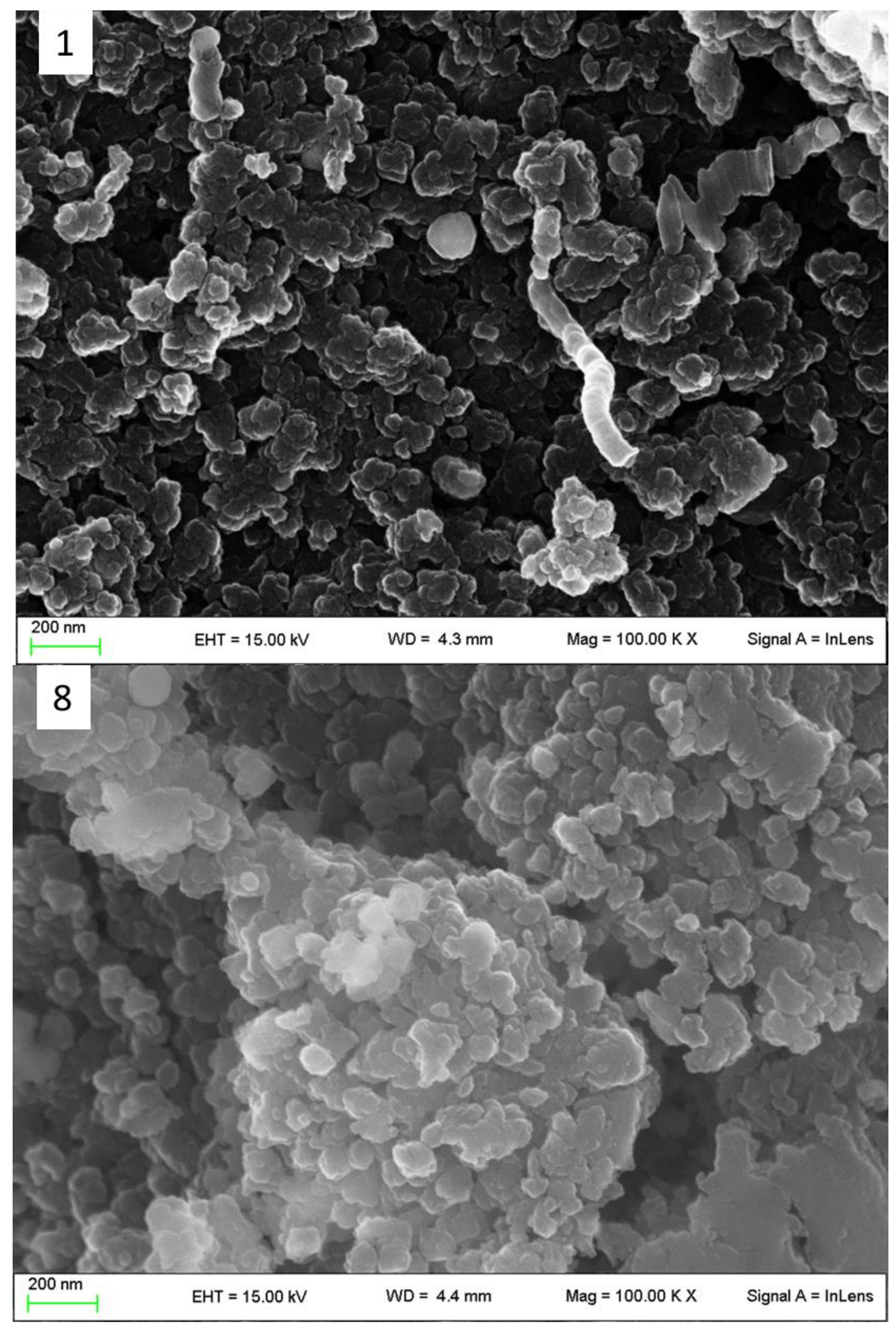


Fig. 9: FE-SEM micrographs of selected spent samples. Sample codes are reported in the relative pictures. Marker size $=1 \mu \mathrm{m}$ for the images in the left column, $=100 \mathrm{~nm}$ for the right column representing the same samples at higher magnification.

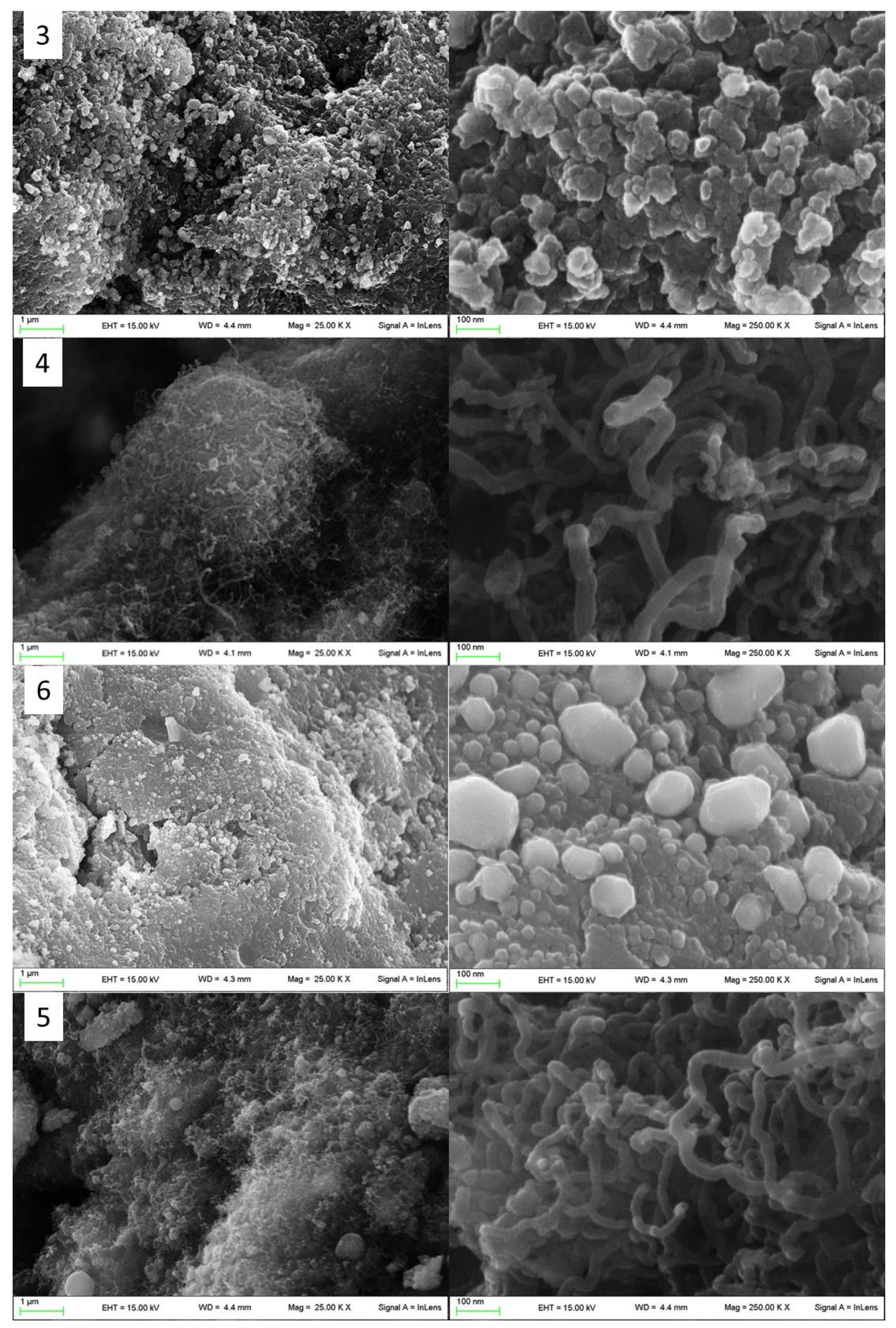


Fig. 10: TEM micrographs of selected spent samples. Sample codes are reported in the relative pictures. Marker size $=100 \mathrm{~nm}$.

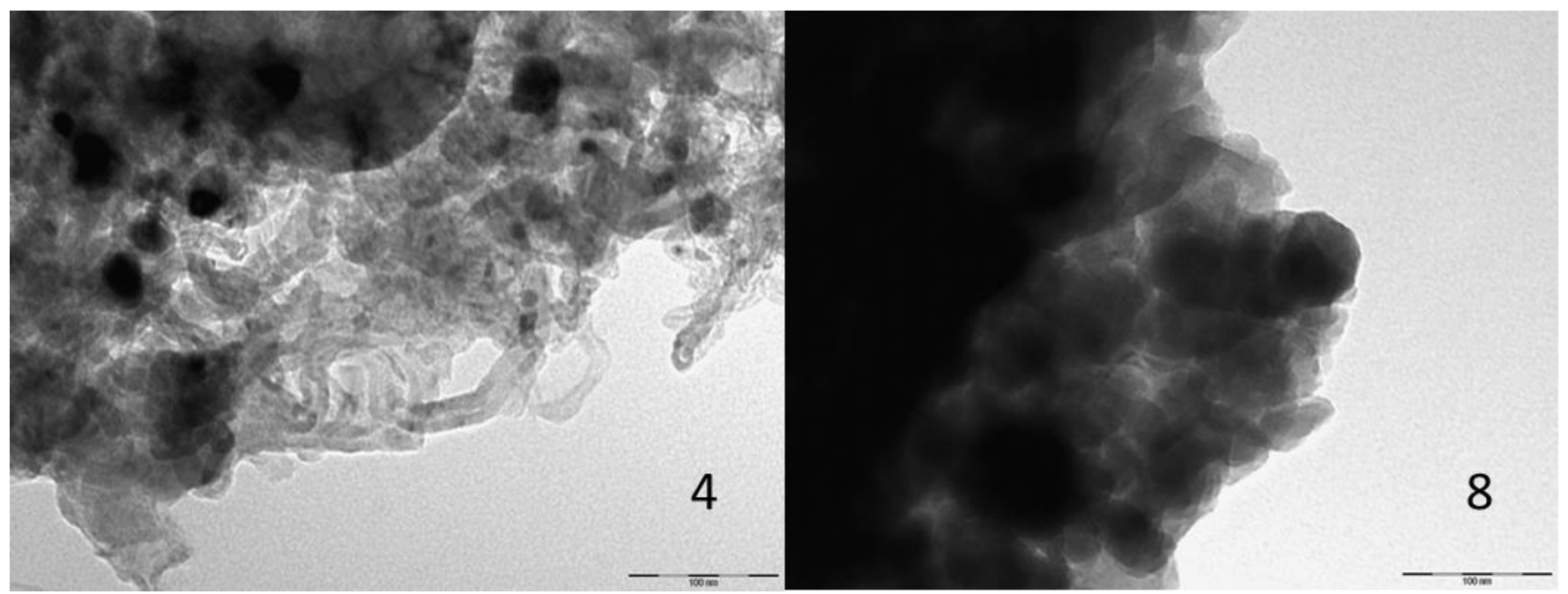

